\title{
Assessment of iodine nutrition in populations: past, present, and future
}

Michael B Zimmermann and Maria Andersson

\begin{abstract}
lodine status has been historically assessed by palpation of the thyroid and reported as goiter rates. Goiter is a functional biomarker that can be applied to both individuals and populations, but it is subjective. lodine status is now assessed using an objective biomarker of exposure, i.e., urinary iodine concentrations (UICs) in spot samples and comparison of the median UIC to UIC cut-offs to categorize population status. This has improved standardization, but inappropriate use of the crude proportion of UICs below the cut-off level of $100 \mu \mathrm{g} / \mathrm{L}$ to estimate the number of iodine-deficient children has led to an overestimation of the prevalence of iodine deficiency. In this review, a new approach is proposed in which UIC data are extrapolated to iodine intakes, adjusted for intraindividual variation, and then interpreted using the estimated average requirement cut-point model. This may allow national programs to define the prevalence of iodine deficiency in the population and to quantify the necessary increase in iodine intakes to ensure sufficiency. In addition, thyroglobulin can be measured on dried blood spots to provide an additional sensitive functional biomarker of iodine status.
\end{abstract}

(c) 2012 International Life Sciences Institute

\section{INTRODUCTION}

Iodine is an essential nutrient for the synthesis of thyroid hormones that are critical for brain development. Iodine deficiency (ID) in utero and in early childhood damages the developing brain, leading to the loss of millions of IQ points globally, making it one of the most important preventable causes of brain damage worldwide. Fortunately, through salt iodization, ID is among the simplest and least expensive of nutrient deficiencies to prevent. The annual costs of salt iodization are estimated at only $\$ 0.02-\$ 0.05$ per child covered, and the costs per child death averted are $\$ 1,000$ and per disability-adjusted life year gained, $\$ 34-36$. ${ }^{1}$

Control of ID is thus a critical and achievable development goal for national governments. In 1952, a World Health Organization (WHO) technical group recommended iodization of all "food salt" in iodine-deficient areas. ${ }^{2}$ Forty years passed before this recommendation was placed squarely on the global health agenda. In 1990, at the U.N. World Summit for Children and the World Health Assembly, and again in 1991 at the Conference on Ending Hidden Hunger, world leaders adopted the ambitious goal of eliminating ID as a public health problem..$^{3-5}$ In 1993, WHO reaffirmed salt iodization as the central strategy to achieve this goal. ${ }^{6}$ Recently, the International Child Development Steering Group identified ID as one of four key global risk factors for impaired child development for which the need for intervention remains urgent. $^{7}$

There has been remarkable progress in the global effort to eliminate ID over the past two decades. In 1993, WHO estimated that 110 countries were affected by goiter and ID. ${ }^{8}$ From 2003 to 2011, the number of iodine-deficient countries decreased from 54 to 32 and the number of countries with adequate iodine intake

Affiliations: MB Zimmermann and M Andersson are with the Human Nutrition Laboratory, Institute of Food, Nutrition, and Health, ETH Zurich, CH-8092 Zurich, Switzerland, and the International Council for the Control of lodine Deficiency Disorders (ICCIDD), CH-8092 Zurich, Switzerland.

Correspondence: MB Zimmermann, Human Nutrition Laboratory, Institute of Food, Nutrition, and Health, ETH Zurich, Schmelzbergstrasse 7, CH-8092 Zurich, Switzerland. E-mail: michael.zimmermann@hest.ethz.ch. Phone: +41-44-632-86-57. Fax: +41-44-632-14-70.

Key words: estimated average requirement, goiter, iodine deficiency, iodine intake, prevalence, salt iodization, thyroglobulin, urinary iodine concentration 
increased from 67 to $105 .{ }^{9}$ Currently, $71 \%$ of the global population has access to iodized salt, up from $20 \%$ in 1990. ${ }^{10}$ Because many countries have eliminated ID or are approaching that goal, their emphasis is now shifting to sustaining these achievements. But salt iodization programs are fragile and require a long-term commitment from governments. Initial enthusiasm may wane as other health problems (e.g., infectious diseases, obesity, and diabetes) move onto the health agenda. In several countries in which ID had been eliminated, salt iodization programs fell apart and ID recurred. ${ }^{11}$ Children in iodinedeficient areas are vulnerable to even short-term lapses in iodized salt programs. ${ }^{12}$

Thus, salt iodization programs, like other public health interventions, require effective, long-term monitoring systems. In 2005, the World Health Assembly called on national governments to report on their iodine nutrition every 3 years. ${ }^{13}$ Periodic measurement of population iodine status is important because both ID and iodine excess have adverse health effects. Monitoring of the salt iodization process and of household coverage with iodized salt are important to ensure that adequately iodized salt reaches at-risk populations. But monitoring must also assess what impact salt iodization and other iodine sources (recognized and unrecognized) are having on the iodine status of the population. This requires the collection of biological samples. The challenge is to choose and apply monitoring indicators that are valid and reliable while keeping costs to a minimum.

In this review to mark the $70^{\text {th }}$ anniversary of Nutrition Reviews, the evolution of iodine programs is discussed and, specifically, how iodine monitoring of populations has changed over the past 70 years. The article covers how and why the time-honored method, the goiter rate (GR), was gradually superseded by measurement of urinary iodine concentration (UIC) and household coverage with iodized salt. It also points out the limitations of these indicators and discusses the drawbacks of focusing only on school-aged children (SAC) and using the distribution of UICs to define the number of individuals affected. Finally, new approaches to assessing iodine nutrition are discussed, including biomarkers of exposure (estimating intakes from UIC distributions) and function (dried blood spot thyroglobulin), and how these promise to provide a much more accurate and complete picture of iodine nutrition of populations.

\section{THE PAST: THYROID SIZE AND GOITER RATE}

Assessment of the size of the thyroid is the historical method by which iodine nutrition is evaluated. There are remarkably detailed descriptions of endemic goiter in different Alpine regions of Europe dating back to the early 1500s. Inspection and palpation for goiter is simple and quick. To assess goiter in field studies, children and adults are examined with the examiner sitting or standing directly in front of the subject, palpating the base of the neck with both thumbs simultaneously. The normal thyroid should not be visible with the neck in the normal position and the lateral lobes may be barely palpable beneath the strap muscles on both sides of the trachea. The surface of the thyroid is smooth and its consistency is firm but compressible, but often the normal thyroid is not palpable.

\section{When is a thyroid a goiter?}

There have been many attempts to try and objectively define when a thyroid is goitrous. In North American goiter surveys in the early 1900s, a normal-sized lobe of the thyroid was assumed to have the size of a lima bean (Phaseolus lunatus) and this was often used as a reference standard for comparison. Other early surveys found it practical to list as positive for endemic goiter a gland that was four to five times the normal size. However, the size of a normal thyroid can vary depending on the age and physical build of the individual. Identifying large visible goiters is straightforward, but experience is needed to accurately identify smaller goiters by palpation, and misclassification is common.

In 1953, at the Food and Agriculture Organization/ WHO Third Conference on Nutrition Problems in Latin America, it was proposed that the dimensions of the thumbnail of the person being examined be used as an approximate reference of normal size of a lateral lobe. ${ }^{14}$ Thus, a gland with lateral lobes greater in size than the terminal phalanges of the thumbs of the person being examined could be considered goitrous. This practical standard was widely adopted for field surveys. In 1960, Perez et al. ${ }^{15}$ proposed a goiter rating scale, but it used arbitrary grading definitions such as "recognized at a considerable distance" or "causes difficulty with respiration and the wearing of clothes." At a Pan American Health Organization/WHO meeting in Lima in 1983, a new classification system ${ }^{16}$ for field studies was proposed that was widely used for the next decade. It recommended the following staging: stage 0 , no goiter; stage I, goiter detectable only by palpation or visible when the neck is fully extended; stage II, goiter visible with the neck in a normal position; stage III, very large goiter recognizable at a distance. The total GR was defined as the prevalence of stages I + II + III within a given region, and an area was empirically defined as endemic for goiter if the GR in primary school-aged children was $>10 \%$.

A decade later, WHO, together with UNICEF and the ICCIDD, ${ }^{6}$ simplified the classification system to produce the current grading system: grade 0 was defined as a thyroid that is not palpable or visible; grade 1 was defined 
as an enlarged gland that is palpable but not visible when the neck is in the normal position (i.e., the thyroid is not visibly enlarged); and previous stages 2 and 3 were combined into a single new grade 2 , defined as a thyroid that is clearly visible when the neck is in a normal position. At the same time, WHO/UNICEF/ICCIDD also revised downward the GR to be considered a public health problem because, in some populations, GRs of 5-10\% were associated with low UICs and/or elevations of thyroid-stimulating hormone (TSH). It was recommended that the GR be used to define severity of ID in populations as follows: $<5 \%$, iodine sufficiency; $5-19 \%$, mild deficiency; $20-29 \%$, moderate deficiency; and $>30 \%$, severe deficiency. ${ }^{17}$ This system of goiter grading and defining ranges of severity remains in use today. A sustained salt iodization program should decrease the GR to $<5 \%$ in SAC, and this indicates disappearance of ID as a significant public health problem. ${ }^{17}$

From the 1960s to the 1990s, children of primary school age, usually defined as 6-12 year olds, increasingly became the preferred target group for goiter surveys. Goiter surveys were nearly always done in SAC for the following reasons: 1) they were readily accessible at schools; 2) samples were often representative because most children go to primary school even in low-income countries; 3 ) this age group is vulnerable to goiter; and 4) diffuse goiter in most SAC will regress with iodine treatment, whereas goiter in older individuals tends to be more fibrotic and less responsive to iodine. Although early authors suggested including pregnant women in goiter surveys because they were vulnerable to goiter even in areas of marginal ID, they were rarely included because representative sampling was more difficult to achieve in this group than in school-based surveys. This focus on SAC carried over into later surveys monitoring excretion of urinary iodine, and, as discussed below, only recently have the limitations of using iodine status in SAC as a proxy for the entire population become widely recognized.

\section{Introduction of thyroid ultrasound}

Assessing iodine status by goiter palpation in areas of moderate to severe ID where many goiters are easily visible is relatively straightforward. In contrast, in areas of mild ID where goiters are smaller, palpation of goiter has poor sensitivity and specificity, even when done by experienced examiners. In such areas, measurement of thyroid volume by ultrasound may be preferable. ${ }^{18}$ With the development of portable, high-resolution equipment in the 1980s, using thyroid ultrasound became possible even in remote areas, where a generator or a car battery can provide electric supply. Experienced examiners can complete a measurement quickly, needing only $2-3 \mathrm{~min}$ per subject. Because of its increased accuracy and precision, thyroid ultrasound increased in popularity in the late 1990s, as visible goiter began to disappear with the spread of iodized salt. In 2003, WHO international reference criteria for thyroid volume by ultrasound in SAC were published, with age- and body surface area-specific $97^{\text {th }}$ percentiles calculated for boys and girls. ${ }^{19}$ In 2007 , WHO described a standard method. ${ }^{19,20}$ Despite this, thyroid ultrasonography as a field tool has not been widely adopted. Thyroid ultrasound equipment is expensive, accurate measurement requires training, and differences in technique can produce large interobserver errors. ${ }^{21}$ For these reasons, and because the limitations of using GRs to monitor the short-term impact of salt iodization are now widely recognized (discussed below), most countries do not routinely use thyroid ultrasound in iodine monitoring.

\section{Potential for iodine deficiency prevalence to be overestimated by use of goiter rate measurement after iodized salt introduction}

In the 1990s, as iodized salt programs were introduced in many countries, there were increasing reports from areas that were previously endemic for goiter that although thyroid size decreased as iodine intake increased, thyroid size did not return to normal for months or years after ID correction, and the GR remained elevated (>5\%), particularly among older children and adults. ${ }^{22,23}$ This problem was already recognized in the early 1800 s by Coindet in Geneva, who noted that goiterous thyroids often did not completely disappear even after long-term treatment with oral iodine. Because of this long lag-time in the resolution of goiter, the GR is difficult to interpret for several years after iodized salt introduction, because it reflects both a population's history of iodine nutrition as well as its present status. Following recommendations from WHO in $1993,{ }^{6}$ most national monitoring programs were measuring both the GR and the UIC, but in contrast to the sluggish response of the GR, UICs rapidly increased into the normal range after the introduction of adequately iodized salt because they reflect recent iodine intake (described below). This resulted in many programs reporting a discrepancy between the degrees of residual ID in the population, as indicated by the UIC compared to the GR. For example, in South African children, after 1 year of mandatory salt iodization, the median UIC was adequate, but the GR by palpation remained unchanged. ${ }^{24}$ A prospective study in West Africa described the time course and pattern of changes in thyroid size and GR in response to the introduction of iodized salt in an area of severe endemic goiter. ${ }^{23}$ Over a 5 -year period in Côte d'Ivoire, thyroid size by ultrasonography and UICs and thyroid hormone concentrations were measured in SAC 
6 months before the introduction of iodized salt and annually for 4 years thereafter. The results showed that 4 years after the introduction of iodized salt and normalization of the median UIC, mean thyroid size had decreased by $56 \%$. However, the GR in SAC remained clearly elevated 4 years after successful introduction of iodized salt, primarily because of persistent goiter in older children. Why do small goiters persist in many children? One possibility is that enlarged thyroids in children who grew up under conditions of ID have irreversible changes in thyroid structure that may not regress completely after the introduction of iodized salt. ${ }^{23}$ If true, achieving a GR $<5 \%$ in SAC may require that the children be born and grow up under conditions of iodine sufficiency. This implies that the lag time to normalization of thyroid size and GR in SAC after the introduction of iodized salt in an area of chronic ID could be a decade or more.

This discrepancy between the median UIC and the GR after the introduction of iodized salt was a source of confusion in many ID control programs. Encouraged by rapid improvements in salt iodine concentrations and the median UIC, governments and program managers monitoring the effect of salt iodization expected a comparable improvement in the GR, but they were often disappointed. In response, monitoring guidelines were revised to emphasize the limitation of the GR in judging the short-term efficacy of salt iodization programs. In 2000, WHO recommended that the median UIC be used as the primary indicator of the impact of iodized salt and it rapidly supplanted the GR as the method of choice. Despite its current unpopularity, the GR in SAC remains an important and sensitive long-term indicator of the success of an iodized salt program. Palpation of goiter is also a useful tool in areas where iodized salt has not yet been introduced or when there is concern that ID may be re-emerging. In such cases, the selection of schools or communities for surveying can be purposive, i.e., on the basis of ID being suspected in that location.

\section{THE PRESENT: MEASUREMENT OF URINARY IODINE CONCENTRATION, DIETARY ASSESSMENT OF IODINE INTAKE, AND HOUSEHOLD COVERAGE WITH IODIZED SALT}

\section{Urinary iodine concentration}

Already in the 1980s, expert groups working to control ID had recognized the limitations of focusing only on goiter. ${ }^{25}$ To emphasize that goiter was only one of many sequelae of ID, Basil Hetzel proposed the term "iodine deficiency disorders (IDD)" to replace "endemic goiter" to describe the broad spectrum of adverse health effects of $\mathrm{ID},{ }^{26}$ and the emphasis of iodine monitoring began to swing toward measurement of urinary iodine (UI).
Moving from a subjective biomarker of function (goiter), to an objective biomarker of exposure (UI), was a step forward because it improved standardization and enabled comparisons to be made among studies.

$\mathrm{UI}$ is an excellent indicator of recent iodine intake because $\geq 92 \%$ of dietary iodine is absorbed and, in healthy, iodine-replete adults, $>90 \%$ is excreted in the urine within $24-48 \mathrm{~h} \cdot{ }^{27,28} \mathrm{UI}$ can be expressed as a $24-\mathrm{h}$ excretion (UIE; $\mu \mathrm{g} /$ day), as a concentration (UIC; $\mu \mathrm{g} / \mathrm{L}$ ), or in relationship to creatinine excretion ( $\mu \mathrm{g}$ iodine/g creatinine). But these are not interchangeable, as discussed below. Because it is impractical to collect $24-\mathrm{h}$ samples in field studies, UICs are usually measured in spot urine collections. In healthy well-nourished adults, daily creatinine excretion is fairly constant at about one gram, so expressing the UIE from spot samples in adults as $\mu \mathrm{g}$ iodine/g creatinine approximates the value in a $24-\mathrm{h}$ collection and reduces variation due to hydration status. ${ }^{29}$ But in malnourished populations with poor protein intakes, daily creatinine excretion is more variable and often lower than $1 \mathrm{~g}^{30}$ In these settings, expressing the UIE as $\mu$ g iodine/g creatinine may introduce greater variation. Due to these limitations and the additional expense of measuring creatinine, the routine co-measurement of creatinine fell out of favor and was replaced by the expression of UIC in $\mu \mathrm{g} / \mathrm{L}$. If a large number of samples are collected, variations in hydration among individuals and day-to-day variation in iodine intake generally even out, so that the median UIC in spot samples correlates well with the median from 24-h samples and with the estimated UIE from creatininecorrected UICs. ${ }^{31}$

But establishing ranges and cut-offs for UICs to define ID in populations was not straightforward. In 1983, the Pan American Health Organization/WHO group recommended that goiter endemias be described by both the GR and by the severity of ID, as reflected in the excretion of UI. ${ }^{25}$ If the GR in a population exceeded $10 \%$, WHO recommended the mean UIE should be measured, and the degree of ID in the population be graded according to the following scale. Grade 1: Goiter endemias with a mean UIE of greater than $50 \mu \mathrm{g} / \mathrm{g}$ creatinine. At this level of iodine intake, no thyroidal or developmental abnormalities are anticipated. Grade 2: Goiter endemias with a mean UIE in the range of $25-50 \mu \mathrm{g} / \mathrm{g}$ creatinine. This group is at risk for hypothyroidism but not for overt cretinism. Grade 3: Goiter endemias with a mean UIE of $<25 \mu \mathrm{g} / \mathrm{g}$ creatinine. There is a high risk for endemic cretinism in such a population.

Similarly, ICCIDD, at its founding meeting in 1986 in Katmandu, proposed that a mean UIC of $<50 \mu \mathrm{g} / \mathrm{L}$ indicated ID and if the UIC level was $<20 \mu \mathrm{g} / \mathrm{L}$, severe ID. ${ }^{32,33}$

Then, in 1988, Pierre Bourdoux, from Brussels, published an article on the use of UI data to evaluate 
population iodine status that proved influential. ${ }^{34} \mathrm{He}$ pointed out the inadequacies of the $\mu \mathrm{g}$ iodine/g creatinine ratio and recommended the use of the concentration in $\mu \mathrm{g} / \mathrm{L}$ in a "sufficient" number of spot urine samples (50-100 as a minimum). He showed that UIC distributions in populations generally do not follow a normal distribution and the limitations of the use of the mean UIC to describe iodine status of a population. Instead, he suggested a simple empiric quantification of the severity of ID in a population by calculating the percentages of subjects with UICs $<100,<50$, and $<20 \mu \mathrm{g} / \mathrm{L}$.

Meanwhile, taking a more rigorous approach to defining UIC cut-offs, experts examined the limited data available on the association between goiter and UIC in populations before iodine prophylaxis. A key study was that of Ascoli and Arroyave (1970) that included data from 186 regions of Central America with goiter palpation in 21,000 people (children and adults) and measurements of UIC and creatinine in over 3,000, with calculation of $24 \mathrm{~h}$ UIE based on urinary creatinine. ${ }^{35}$ This study found that endemic goiter (defined at that time as a GR $>10 \%$ ) was found in the following areas: 1) all areas in which the mean UIE was $<25 \mu \mathrm{g} /$ day; 2 ) most areas in which the mean UIE was $25-49 \mu \mathrm{g}$ /day; 3 ) about

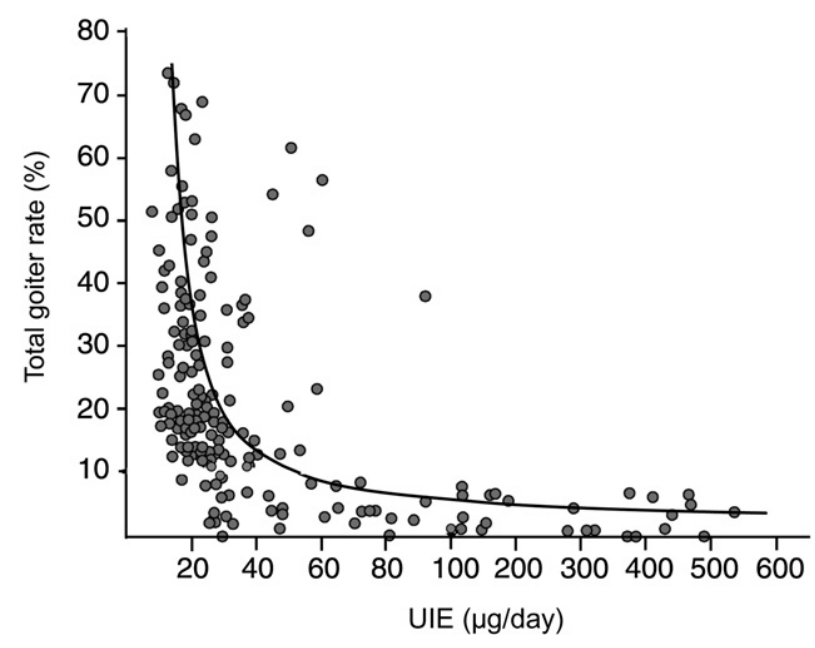

Figure 1 Correlation between goiter rate and urinary iodine excretion (UIE) in the general population of 186 localities in Central America during the period 19651967. Each point represents an average of values from subjects of 20 randomly selected families. Goiter and UIE were measured in 21,611 and 3,181 subjects, respectively.

Data from Ascoli and Arroyave. ${ }^{35}$ Reprinted from Best Practice \& Research Clinical Endocrinology \& Metabolism, Vol 24, Iss 1. Laurberg, Cerqueira, Ovesen, Rasmussen, Perrild, Andersen, Pedersen, and Carlé. lodine intake as a determinant of thyroid disorders in populations, pp13-27, (c) 2010, with permission from Elsevier.

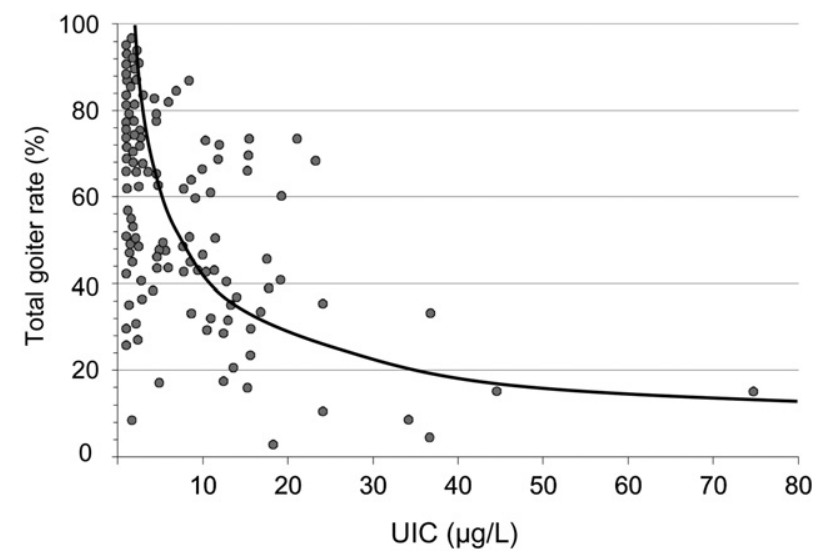

Figure 2 Correlation between goiter and urinary iodine concentration (UIC) in women of reproductive age $(n=2,484)$ from 86 villages in Slovakia. Each point represents an average of values from 10 to 40 women. Adapted from Langer. ${ }^{38}$

one-third of areas in which the mean UIE was $50-99 \mu \mathrm{g} /$ day; and 4) virtually none of the areas in which UIE was $>100 \mu \mathrm{g} /$ day (Figure 1).

Based largely on these data suggesting the GR was $<10 \%$ when the mean UIE was $>100 \mu \mathrm{g}$ per day, WHO endorsed a median UIC of $>100 \mu \mathrm{g}$ per liter as an indicator of iodine sufficiency in a population (1993). ${ }^{6}$ But clearly the UIC in $\mu \mathrm{g} / \mathrm{L}$ is not necessarily interchangeable with the $24 \mathrm{~h}$ UIE ( $\mu \mathrm{g} / 24 \mathrm{~h}$ ), as it depends on daily urine volume. ${ }^{36}$ If the daily volume of urine produced by a group approximates $1 \mathrm{~L} /$ day, as it does in healthy primary SAC, then the UIC $(\mu \mathrm{g} / \mathrm{L})$ is interchangeable with the $24 \mathrm{~h}$ UIE $(\mu \mathrm{g} / 24 \mathrm{~h})$. But these two indices are not comparable in older adolescents and adults, in whom the mean daily urine volume approximates $1.5 \mathrm{~L} / \mathrm{day}^{37}$; thus, the UIC $(\mu \mathrm{g} / \mathrm{L})$ in spot samples is usually about $60-65 \%$ of the amount excreted in $24 \mathrm{~h}$. Therefore, in adults, a UIE of $100 \mu \mathrm{g} / 24 \mathrm{~h}$ corresponds to a UIC of approximately $60-70 \mu \mathrm{g} / \mathrm{L}$. Thus, the extrapolation from the observed association between increasing goiter and a UIE $<100 \mu \mathrm{g} /$ $24 \mathrm{~h}^{35}$ to a UIC below $100 \mu \mathrm{g} / \mathrm{L}$ as indicative of ID may have been applicable in children but was not correct for adults. In practical terms, this resulted in an inappropriate increase in the recommended iodine intake for adults without any real evidence that this was needed to avoid ID. The proper interpretation of these data would have produced a cut-off for ID using the median UI in SAC of $100 \mu \mathrm{g} / \mathrm{L}$ and a cut-off of about $60-70 \mu \mathrm{g} / \mathrm{L}$ for adults. This adult cut-off is supported by a large study of young women in Slovakia conducted before the introduction of iodine prophylaxis; in this study, GRs were estimated by palpation in approximately 10,000 women and UICs in spot samples (expressed as $\mu \mathrm{g} / \mathrm{L}$ ) were measured in approximately $2,500^{38}$ (Figure 2). The results indicated 
Table 1 Epidemiological criteria for assessing iodine status on the basis of median and/or range of urinary iodine concentration values in a population.

\begin{tabular}{|c|c|c|}
\hline Median UIC & lodine intake & lodine nutrition status \\
\hline \multicolumn{3}{|c|}{ School-aged children } \\
\hline$<20 \mu \mathrm{g} / \mathrm{L}$ & Insufficient & Severe iodine deficiency \\
\hline $20-49 \mu \mathrm{g} / \mathrm{L}$ & Insufficient & Moderate iodine deficiency \\
\hline $50-99 \mu \mathrm{g} / \mathrm{L}$ & Insufficient & Mild iodine deficiency \\
\hline $100-199 \mu \mathrm{g} / \mathrm{L}$ & Adequate & Optimal \\
\hline $200-299 \mu \mathrm{g} / \mathrm{L}$ & Above requirements & $\begin{array}{l}\text { Likely to provide adequate intake for pregnant/lactating women, } \\
\text { but may pose a slight risk of more than adequate intake in the } \\
\text { overall population }\end{array}$ \\
\hline$\geq 300 \mu \mathrm{g} / \mathrm{L}$ & Excessive & $\begin{array}{l}\text { Risk of adverse health consequences (iodine-induced } \\
\text { hyperthyroidism, autoimmune thyroid disease) }\end{array}$ \\
\hline \multicolumn{3}{|l|}{ Pregnant women } \\
\hline$<150 \mu \mathrm{g} / \mathrm{L}$ & Insufficient & lodine deficiency \\
\hline $150-249 \mu \mathrm{g} / \mathrm{L}$ & Adequate & Optimal \\
\hline $250-499 \mu \mathrm{g} / \mathrm{L}$ & Above requirements & - \\
\hline$\geq 500 \mu \mathrm{g} / \mathrm{L}$ & Excessive $^{\mathrm{a}}$ & - \\
\hline \multicolumn{3}{|l|}{ Lactating women } \\
\hline$\geq 100 \mu \mathrm{g} / \mathrm{L}$ & Adequate & Optimal \\
\hline
\end{tabular}

${ }^{\mathrm{a}}$ In excess of the amount required to prevent and control iodine deficiency.

Adapted with permission from the World Health Organization. ${ }^{17}$

there was no increase in goiter in areas where the mean UIC was $>60 \mu \mathrm{g} / \mathrm{L}$. This lower cut-off for the median UIC for adults is also supported by the EAR cut-point approach to define low iodine intakes, as discussed below.

In 1992, at a joint WHO/UNICEF/ICCIDD consultation, it was first proposed that the goal of monitoring progress toward eliminating IDD as a public health problem was to achieve a median UIC of $100 \mu \mathrm{g} / \mathrm{L}$ in SAC, with less than $20 \%$ of subjects having UICs below $50 \mu \mathrm{g} / \mathrm{L}{ }^{6}$ The UIC cut-off of $100 \mu \mathrm{g} / \mathrm{L}$ in SAC was supported by a multicenter study in which UIC and thyroid volume were measured in 5,709 European school children. ${ }^{39}$ Although this study may have overestimated the goiter prevalence, ${ }^{19}$ the authors concluded that goiter begins to appear in SAC below the critical UIC threshold of $100 \mu \mathrm{g} / \mathrm{L}$, and this agrees well with the earlier data from SAC in the report of Ascoli and Arroyave. ${ }^{35}$

By the mid-1990s, the median UIC $<100 \mu \mathrm{g} / \mathrm{L}$ in SAC had become the most widely used biochemical measure of ID in a population. For national, school-based surveys of iodine nutrition, the median UIC from a representative sample of spot urine collections from approximately 1,200 children (30 sampling clusters $\times 40$ children per cluster) could be used to derive the median UIC used to classify a country's iodine status (Table 1). ${ }^{6,17}$ In later WHO recommendations, ${ }^{17,40}$ it was proposed that the median UIC cut-off of $100 \mu \mathrm{g} / \mathrm{L}$ could also be applied to adults. But, as discussed above, this is incorrect: use of this cut-off in young women of reproductive age, although it is increasingly done, results in a falsely high prevalence of women with inadequate intakes. The correct cut-off for median UIC in adult women remains uncertain but is likely to be close to $60-70 \mu \mathrm{g} / \mathrm{L}$.
Starting in the 1990s there was a remarkable expansion of coverage of the global population represented by UIC surveys. By 2011, UIC survey data covered $96.1 \%$ of the world's population of SAC. ${ }^{9}$ Although data are lacking for 45 countries, these countries (mostly smaller islands) contain only $3.9 \%$ of the world's population of SAC. Many regional and national laboratories were established that could accurately measure UICs, and over the past decade, the U.S. Centers for Disease Control and Prevention has provided rigorous external quality control through its international EQUIP program. ${ }^{41}$

Potential to overestimate the true prevalence of iodine deficiency when using crude UIC data distributions from spot samples to define the number of individuals affected by low intakes. Although the median UIC is a good population indicator of iodine status, the distribution of UIC around the median in iodine surveys is often misinterpreted in an attempt to define the number of individuals who are deficient. A common mistake is to assume that all subjects with a spot UIC $<100 \mu \mathrm{g} / \mathrm{L}$ are iodine deficient. But dietary iodine intake and therefore UIC are highly variable from day to day. In iodine-sufficient countries where most iodine intake comes from iodized salt, UIC (both spot and 24-h urine collections) show an individual day-to-day variation of $30-40 \%$ (Figure 3a,b). ${ }^{29,31,42}$ Therefore, in an individual whose average daily iodine intake is adequate to maintain normal thyroidal iodine stores, iodine intake will show wide daily variation that will result in many individual days when a UIC value will be less than adequate. Thus, even in populations in which iodized salt ensures adequate thyroid stores, there will nearly always be 
(a)

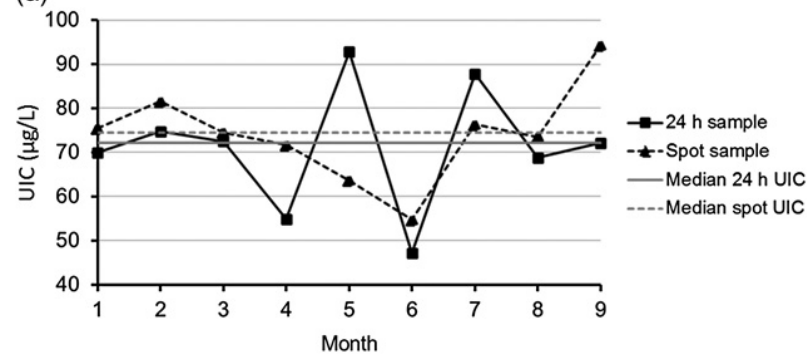

Figure $3 a$ Day-to-day variation of urinary iodine concentration (UIC) in 24-h and spot samples from one healthy adult woman in an iodine-sufficient population obtained over a 9-day period.

Data adapted from König et al. ${ }^{31}$

individuals with a UIC $<100 \mu \mathrm{g} / \mathrm{L}$ on the day of the survey, but they are not truly iodine deficient.

This common error in UIC interpretation was unfortunately indirectly endorsed by WHO. When pushed to define the number of individuals with low iodine intakes in order to give prevalence estimates, WHO made the decision to classify all children in iodine surveys with a spot UIC $<100 \mu \mathrm{g} / \mathrm{L}$ as having low iodine intakes. ${ }^{43}$ This allowed WHO to generate regional and global prevalence data, but the approach also led to the apparent paradox that a country like Switzerland, with a model iodized salt program, a national median UIC of $120 \mu \mathrm{g} / \mathrm{L}$ and a GR of $<3 \%$ in $\mathrm{SAC}^{44}$ is classified as having "optimal" country iodine status, but at the same time $36 \%$ of the population is classified as having inadequate iodine intake. ${ }^{9}$

Since 2003, this approach has been used to monitor regional and global progress by estimating the number of individuals with low iodine intake. ${ }^{9,43,45}$ It overestimates the true prevalence of ID (see below) and has contributed to the perception of a global slowdown in progress to control ID when looking at trends in numbers affected rather than in changes in national iodine status based on the median UIC. Over the past decade, the number of countries with adequate iodine status based on the national median UIC has jumped from 67 to $105 .{ }^{9}$ During the same period, the global prevalence of SAC with low iodine intake has fallen only $6 \%$, from $36 \%$ in 2003 to $30 \%$ in 2011. This method has resulted in the paradox that in 2011, 3 out of 4 children classified as having low iodine intake are living in countries that are iodine sufficient based on the national median UIC, while only 1 in 4 with low intakes are living in countries with inadequate national medians. In practical terms, continued use of this method to define the prevalence of ID will make the global goal of elimination of ID impossible to achieve.

This error in UIC interpretation may do harm in that it implies that countries with already adequate national median UICs should try and minimize the percentage of (b)

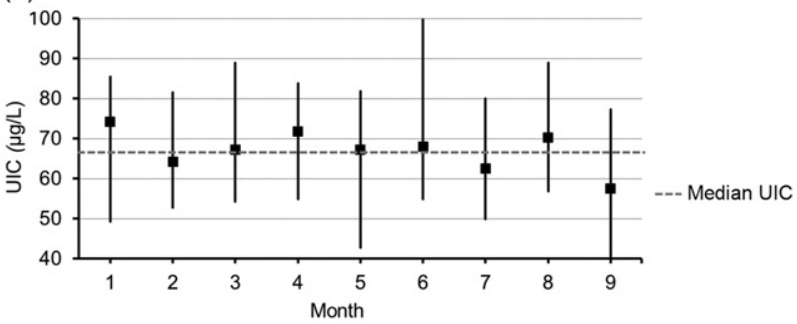

Figure $3 b$ Median urinary iodine concentration (UIC) in spot samples from 22 healthy adult women in an iodine-sufficient population obtained over a 9-month period. Median UIC ( $95 \% \mathrm{Cl}$, by bootstrap).

Data adapted from König et al. ${ }^{31}$

the population with a UIC $<100 \mu \mathrm{g} / \mathrm{L}$ by increasing the iodine content of salt and increasing intakes. But high intakes of iodine should be avoided, especially in populations with a history of chronic ID, because a large increase in iodine intake may precipitate autoimmune thyroid disease and/or hyperthyroidism. ${ }^{46,47}$ Based on the national median UIC, in 2011, 11 countries have iodine intakes above the $300 \mu \mathrm{g} / \mathrm{L}$ threshold that WHO classifies as "excessive.", 17 These data emphasize the importance of regular monitoring of iodine status to detect not only low but also excessive intakes of iodine.

A new approach is proposed below in which UIC survey data adjusted for intra-individual variation is extrapolated to iodine intakes and then interpreted using the EAR cut-point model. This approach may allow national programs to accurately define the prevalence of ID in the population and quantify the necessary increase in iodine intakes to ensure sufficiency.

Potential to miss iodine deficiency in vulnerable groups when focusing only on school-aged children. As discussed above, early goiter surveys focused on SAC, and if the GR in SAC was low, it was generally assumed that iodized salt was providing adequate iodine to the entire population. As assessment of iodine status using UICs gradually replaced goiter surveys, the target group in nearly all studies remained SAC. In 2011, an assessment of 148 countries with data showed that 107 estimates were based on national studies conducted in SAC. ${ }^{9}$ This focus on SAC simplified iodine monitoring but it was too narrow, because the groups most vulnerable to irreversible damage from ID are developing fetuses (via pregnant women) and infants. ${ }^{48}$ Later studies demonstrated that iodine status in pregnant women or in women of reproductive age are not necessarily represented by the iodine status of schoolchildren (Figure 4). ${ }^{49,50}$ In some countries, women can have low intakes even when SAC have optimal intakes. This may be particularly true in 


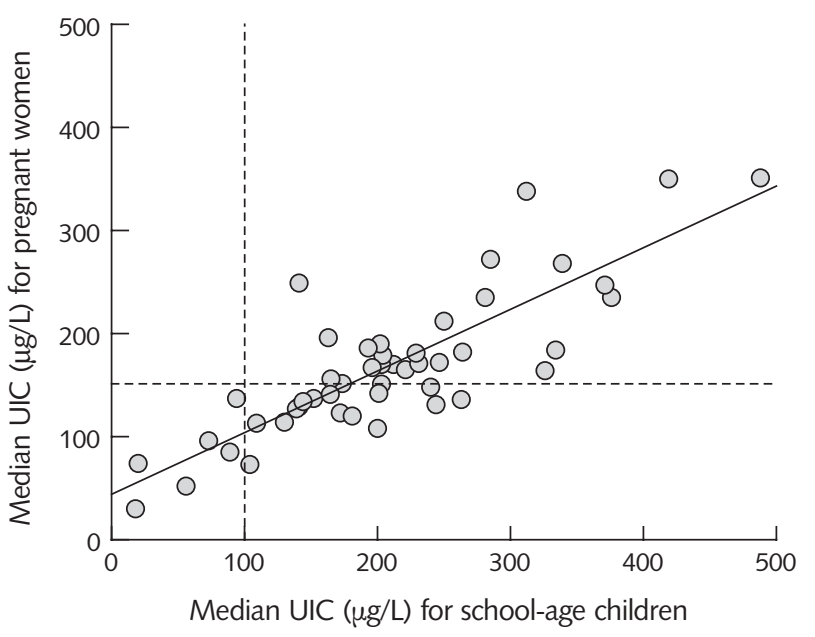

Figure 4 Scatter plot of median urinary iodine concentration (UIC) in pregnant women and school-age children $(\boldsymbol{n}=\mathbf{4 8})$. Each point represents a survey pair. The horizontal dashed line indicates the cutoff value for inadequate median UIC for pregnant women $(<150 \mu \mathrm{g} / \mathrm{L})$, and the vertical dashed line indicates the cutoff value for inadequate median UIC for school-age children $(<100 \mu \mathrm{g} / \mathrm{L})$. The regression line equation is $y=44.59+0.59(x)$, and $R^{2}=0.69$. Reprinted with permission from Wong et al., the Food and Nutrition Bulletin. ${ }^{50}$

populations eating Western diets since a substantial proportion of total iodine intake in such diets comes from milk, and milk consumption is typically highest in children. $^{51}$

Although monitoring of iodine status in pregnant women and in women of reproductive age is becoming increasingly popular, ${ }^{17,52}$ only a limited number of countries have completed UIC surveys in these groups on the national or large subnational level. Because there are insufficient data to directly estimate the regional or global prevalence of low iodine intake in these important target groups, the median UIC in SAC continues to be used as a proxy for the general population in most surveys.

\section{Dietary iodine requirements}

The dietary reference intakes (DRI) for iodine, set by the Institute of Medicine (IOM) in the United States, are provided as three different measures to describe the distribution of nutrient requirements; the estimated average requirement (EAR), the recommended dietary allowance (RDA), and the adequate intake (AI) ${ }^{53,54}$ (Table 2). The DRIs apply to usual intakes over time and are intended for a generally healthy population. ${ }^{55}$ The EAR for iodine has been derived from balance studies ${ }^{56-60}$ and from studies measuring the daily iodine uptake, accumulation, and turnover in the thyroid gland by using radioactive iodine in euthyroid adult subjects. ${ }^{61,62}$ The average thyroidal iodine turnover in these studies was in the range of $91-97 \mu \mathrm{g} / \mathrm{day}$, with a coefficient of variation of $20 \%$, i.e., a standard deviation (SD) of $19 \mu \mathrm{g} /$ day. ${ }^{53,62}$ The EAR for adults has, therefore, been set at $95 \mu \mathrm{g} / \mathrm{day} .{ }^{53} \mathrm{The}$ RDA of $150 \mu \mathrm{g} /$ day is calculated from the EAR by adding $2 \mathrm{SD}$ to the EAR and rounding to the nearest $50 \mu \mathrm{g} .{ }^{17,53}$ The basis for the DRIs for iodine in other age and population groups has been reviewed elsewhere. ${ }^{48,53}$

\section{Dietary assessment of iodine intake}

Dietary sources of iodine. In countries in which salt is iodized, it is generally the main dietary source of iodine, i.e., household salt or salt used in food production. ${ }^{63,64}$ WHO recommends levels of $20-40 \mathrm{mg}$ iodine per $\mathrm{kg}$ salt. ${ }^{65}$ Commercially available iodized salt contains iodine in the range of $15-80 \mathrm{mg}$ iodine per kg salt. ${ }^{63,66} \mathrm{In}$ settings in which foods are mainly prepared at home, household (table) salt is the major iodine source. In contrast, in industrialized countries, salt used in processed foods contributes approximately $60-80 \%$ of the total salt

Table 2 Recommended dietary intakes of iodine by age or population group.

\begin{tabular}{|c|c|c|c|c|c|}
\hline \multirow[t]{2}{*}{ Age or population group } & \multicolumn{3}{|l|}{$\mathrm{IOM}^{\mathrm{a}}$} & \multicolumn{2}{|l|}{$\mathrm{WHO}^{\mathrm{b}}$} \\
\hline & $\begin{array}{l}\text { EAR } \\
(\mu \mathrm{g} / \text { day })\end{array}$ & $\begin{array}{l}\text { Al or RDA } \\
\text { ( } \mu \mathrm{g} / \text { day) }\end{array}$ & $\begin{array}{l}\text { Tolerable UL } \\
\text { ( } \mathrm{g} / \text { day) }\end{array}$ & Age or population group & $\begin{array}{l}\text { RNI } \\
\text { ( } \mu \mathrm{g} / \text { day) }\end{array}$ \\
\hline Infants 0-12 months & - & $110-130^{c}$ & $\ldots$ & Children $0-5$ years & 90 \\
\hline Children $1-8$ years & 65 & 90 & $200-300$ & Children $6-12$ years & 120 \\
\hline Children $9-13$ years & 73 & 120 & 600 & $\ldots$ & $\ldots$ \\
\hline Adults $\geq 14$ years & 95 & 150 & $900-1,100$ & Adults $>12$ years & 150 \\
\hline Pregnant women & 160 & 220 & $900-1,100$ & Pregnancy & 250 \\
\hline Lactating women & 200 & 290 & $900-1,100$ & Lactation & 250 \\
\hline $\begin{array}{l}\text { a Data from the Institute of } \mathrm{N} \\
\mathrm{b} \text { Data from the World Health } \\
{ }^{\mathrm{C}} \text { Values are adequate intake. } \\
\text { Abbreviations: Al, adequate in }\end{array}$ & inization. ${ }^{17}$ & rac & (1) & van & ded \\
\hline
\end{tabular}


intake. ${ }^{67-69}$ The main salt sources from processed foods in typical Western diets are bread, dairy products (see below), and processed meat. ${ }^{70-72}$ The total amount of dietary iodine from salt in industrialized countries with iodized salt varies depending on the type of food products produced with iodized salt and the level of iodine fortification.

However, in most countries, much of the salt used in food production is not iodized. In industrialized countries, where average daily salt consumption in adults is approximately $10 \mathrm{~g} /$ day but only $1-2 \mathrm{~g} /$ day is household salt, if the food industry were to use noniodized salt and only household salt were to be iodized, then total iodine intake from iodized salt would only be about $40 \mu \mathrm{g} / \mathrm{day}$, which is far below the daily requirement for all age groups. But there are good examples of how the use of iodized salt by the food industry can contribute to iodine sufficiency. In Denmark and the Netherlands, for example, most salt used by the baking industry is iodized, and this is a major contributor to iodine sufficiency. ${ }^{73-75}$

Although their native iodine content is low, dairy products are other major sources of dietary iodine due to iodine fortification of cattle fodder and/or iodine residues remaining in milk from disinfecting agents (iodophors) used in dairying. ${ }^{76-80}$ Remarkably, in countries without iodized salt, adventitious iodine in milk is the principal dietary source of iodine; e.g., in the United Kingdom and Norway ${ }^{81,82}$ Milk and dairy products are particularly important iodine sources for children..$^{51,64,78,82,83}$ Saltwater fish and seafood have high natural iodine content, ${ }^{84}$ but their contribution to the overall dietary iodine intake is modest unless consumed every day. ${ }^{64,82}$ Some types of seaweeds are high in iodine and the iodine intake in seaweed-consuming populations may consequently be high. ${ }^{85,86}$ Drinking water drawn from certain aquifers or water disinfected with iodine can also be rich in iodine. ${ }^{87,88}$

Variability of iodine intake. Individual levels of iodine intake can vary considerably from day to day, depending on the types of iodine-containing foods consumed and their iodine content. The main variation is due to daily differences in salt intake, ${ }^{89,90}$ i.e., decisions to consume processed food products with iodized salt and the discretionary amount of iodized salt. The iodine content of other foods may vary due to natural variation in iodine content. ${ }^{77,78,91}$ For example, milk iodine concentration can vary between regions of origin, ${ }^{77,81,92}$ with season, ${ }^{76,92}$ between conventional milk and organic milk, ${ }^{81}$ and with fat content. ${ }^{92}$

Methods used to assess dietary iodine intake. Dietary assessment of iodine intake aims to measure the average habitual long-term iodine intake from iodine-containing foods, i.e., food choices, amounts consumed, and frequency of consumption. ${ }^{93,94}$ The three major instruments are food frequency questionnaires (FFQ), ${ }^{74,95,96}$ food diaries or 24-h food intake recalls, ${ }^{97}$ and weighed food records. ${ }^{64}$ FFQs assess the frequency and portion sizes of iodine-containing foods and/or food groups consumed over a predefined time-frame (usually 1 year). ${ }^{93,94}$ The FFQ method captures iodine-rich sources that are irregularly consumed and accounts, to some extent, for day-to-day variation in the overall consumption patterns. Although an FFQ may include questions on discretionary salt added at the table or in cooking, it is difficult to accurately quantify the total amount of iodized salt consumed. Therefore, the FFQ method is not a reliable quantitative method for assessing total iodine intake. Food diaries or 24-h recalls measure short-term intakes. ${ }^{93,94}$ To capture the day-to-day variation in dietary iodine intake, at least 10 repeated assessment days and/or a large sample size is needed, as shown for 24-h UIC collections. ${ }^{31}$ Dietary recall is often inaccurate with regard to salt intake and it generally underestimates salt consumption..$^{98,99}$ The lack of accuracy in measuring iodine intake from iodized salt is, thus, a major limitation of dietary assessment. ${ }^{95,100,101}$

Food composition tables. All assessment methods require information on the iodine content of foods to calculate the iodine intake. Food iodine content can be accurately measured by inductively coupled plasma mass spectrometry (ICP-MS). ${ }^{78}$ Unfortunately, only a limited number of laboratories worldwide perform food analysis with ICP-MS. The quality of iodine data in food composition tables depends on whether the food iodine analysis is up-to-date and to what extent natural variability in iodine content is taken into account. Food composition databases generally contain information on the salt content of foods, but they rarely specify if the salt used in processed foods is iodized or not. The food industry often fails to declare whether iodized salt has been used in food production and, even if they do, there may be differences in salt iodine content between brands of the same product or even for the same brand sold in different countries.

In summary, dietary assessment of iodine intake is challenging and the large day-to-day variation makes it difficult to quantify the "usual" iodine intake. However, dietary data can be used to identify the most significant food sources of iodine. This information is useful to design or adapt iodine intervention strategies. Simulation models can be used to predict anticipated effects of changes in the level of iodine fortification, the impact of reduced salt intake, and changes in food vehicles used for iodine fortification. ${ }^{63,75,102,103}$ 


\section{Monitoring iodized salt programs by measuring the percentage of households using iodized salt}

The iodization of household salt is monitored in standardized household surveys in many lower-income countries. Since the mid-1990s, UNICEF has assisted countries in collecting health data through its international household survey initiative, the Multiple Indicator Cluster Surveys. Another example is the Demographic and Health Surveys program from the US Agency for International Development. These surveys have large sample sizes (usually between 5,000 and 30,000 households) and typically are conducted about every 5 years, to allow comparisons over time to be made. The testing of household salt samples is usually done with simple rapid test kits (RTKs). A drop of starch-based solution placed onto salt produces a blue/purple color if the salt contains iodine. RTKs directly assess the penetration and coverage of a population by iodized salt. This approach has clear advantages in iodine monitoring. It is noninvasive, simple, and inexpensive, and it provides immediate visible results.

In low-resource settings, household coverage with iodized salt may be the only indicator used to monitor iodine status in a population. But this approach is inadequate for several reasons. First, RTKs are qualitative not quantitative; they can detect the presence of iodine in a salt sample, but they cannot accurately quantify the amount. Thus, salt that is not adequately iodized (adequately iodized salt is usually defined as containing $>15$ and $<40 \mathrm{ppm}$ iodine) will test positive but will not deliver adequate iodine to populations. Second, in many middle- and high-income countries, salt intake comes mainly from purchased processed foods. Little salt is added in the home, so even if household coverage with adequately iodized salt is high, iodine intakes may not be adequate unless the food industry uses iodized salt. Finally, in some areas, other sources of iodine (such as iodine-rich groundwater) can contribute large amounts of dietary iodine, and iodine intakes may be excessive in a population, but household coverage data do not reflect this.

To ensure salt is adequately iodized and not overiodized, it is now recommended that RTK data be backed up by quantitative titration. The iodine content of salt is measured by titrating the iodine with sodium thiosulphate using starch as an external indicator. Although it is accurate and requires only basic equipment, titration is time-consuming and requires some scientific training. An alternative is to use a portable spectrophotometer, such as the WYD checker to back up RTK results, but it is much more expensive than titration. Titration is recommended for determining iodine in salt at points of the salt distribution system (e.g., import points, manufacturers) where accurate testing is required.
UNICEF uses the data from household surveys of iodized salt to estimate the number of newborns born each year who are protected against mental and physical impairment from in utero ID. ${ }^{104}$ For example, in a country known to be iodine deficient before the introduction of iodized salt, if $50 \%$ of households are using salt that tests positive with RTKs, then the yearly birth rate is multiplied by 0.5 to derive the number of newborns born protected against ID. Because the developing fetus is the life stage most vulnerable to irreversible damage from ID, if this number could be quantified, this would be an important, relevant index of the potential health benefits of iodized salt programs. However, because of the limitations discussed above, it is problematic to extrapolate from household coverage to newborns protected. If the dietary iodine intake of women of reproductive age and/or pregnant women could be estimated and the prevalence of low intakes in these groups determined, this would likely provide a better index of the number of newborns protected from ID by iodized salt. This may be possible using the EAR cut-point approach and the distribution of UICs in women, as described in the next section.

\section{THE FUTURE: ESTIMATION OF IODINE DEFICIENCY PREVALENCE USING THE ESTIMATED AVERAGE REQUIREMENT CUT-POINT METHOD AND DRIED BLOOD SPOT METHODS TO ASSESS THYROID FUNCTION}

In healthy adults, the mean daily uptake and release (turnover) of iodine by the thyroid is approximately $95 \mu \mathrm{g} .{ }^{62,105}$ Thus, to achieve iodine balance (sufficiency), the daily iodine intake must be sufficient to enable the thyroid to turn over $95 \mu \mathrm{g}$ iodine per day to maintain euthyroidism. Short-term deficits in iodine intake can be buffered by intrathyroidal stores (up to $20 \mathrm{mg}$ in iodinesufficient areas) and increased fractional clearance of circulating iodine. ${ }^{105}$ However, if iodine intakes are chronically low, thyroidal iodine reserves will be gradually depleted and iodine turnover will need to be increasingly covered by dietary iodine supply (Figure 5). Eventually, low dietary intakes will limit thyroid hormone synthesis. ${ }^{106}$ Thus, ID can be broadly defined in two phases: 1) as inadequate iodine intake (assessed by exposure biomarkers such as UIC) that, when chronic, leads to 2) thyroid dysfunction (assessed by functional biomarkers, e.g., thyroid size, thyroid hormones). Inadequate iodine intake in individuals is defined as that below the $\mathrm{RDA} / \mathrm{RNI}$, whereas inadequate intake of populations is defined as intakes below the EAR..$^{55,107-109}$ The next section describes the principal ideas behind two new methods to monitor the two phases of ID in populations, i.e., 1) EAR cut-point estimates considering the iodine EAR (exposure) and 2) prevalence of thyroid dysfunction based on dried blood spot thyroglobulin (function). 


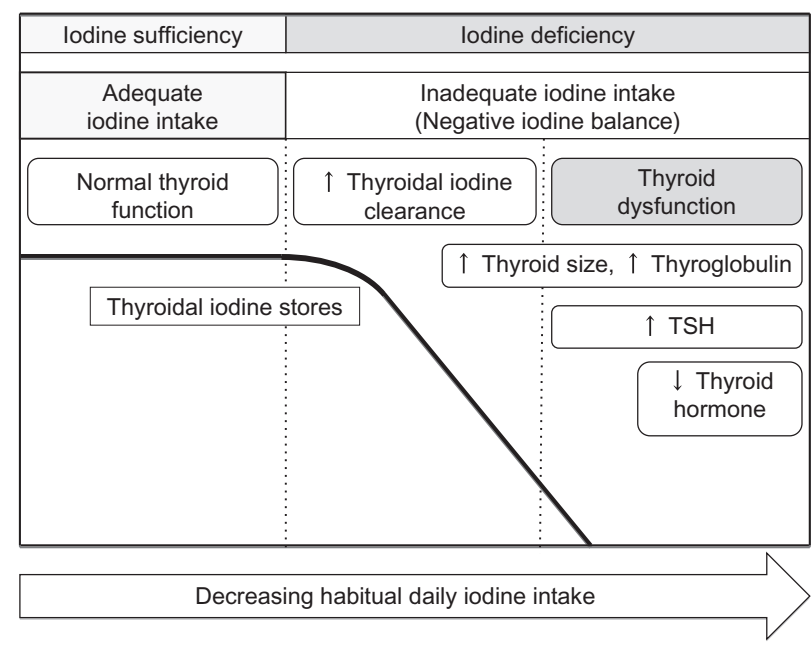

Figure 5 The physiological stages of iodine status. The graph illustrates a simplified model of human iodine and thyroid status at different stages (left to right) of iodine intake: sufficient iodine intake, low iodine intake without thyroid dysfunction, and, finally, low iodine intake with hypothyroidism. The three stages are separated by vertical dashed bars. The scientific evidence is limited with regard to the absolute levels of habitual daily iodine intake at which thyroid stores decrease and thyroid dysfunction occurs. Abbreviation: TSH, thyroid-stimulating hormone.

\section{Estimation of iodine intake in populations using urinary iodine concentration measurement}

UIC is considered a reliable biomarker of recent iodine intake in populations at all levels of chronic iodine intake: in positive iodine balance, more than $90 \%$ of ingested iodine is excreted in the urine. A major advantage of UIC over dietary assessment and household salt consumption data is that UIC represents the total iodine intake from all dietary sources. The concentration of iodine in the urine depends on the urine volume, and the daily iodine intake can be estimated from spot UIC by estimating the daily UIE from the creatinine concentration..$^{29,31}$ The following simplified equation to calculate daily iodine intake has been proposed by the $\mathrm{IOM}^{53}$ :

$$
\begin{aligned}
\text { Iodine intake }\left(\mu \mathrm{g} \cdot \mathrm{L}^{-1}\right)= & \mathrm{UIC}\left(\mu \mathrm{g} \cdot \mathrm{L}^{-1}\right) / 0.92 \cdot \\
& \left(0.0009 \mathrm{~L} \cdot \mathrm{h}^{-1} \cdot \mathrm{kg}^{-1} \cdot 24 \mathrm{~h} \cdot \mathrm{d}^{-1}\right) \\
& \text { weight }(\mathrm{kg})
\end{aligned}
$$

In this equation, 0.92 refers to $92 \%$ bioavailability and $0.0009 \mathrm{~L}^{\circ} \mathrm{h}^{-1} \mathrm{~kg}^{-1}$ refers to excreted urine volume from studies in children. Although body weight is poorly correlated with urine volume in adults, the factor of $0.0009 \mathrm{~L}^{\cdot} \mathrm{h}^{-1} \mathrm{~kg}^{-1}$ is still a good approximation considering an average 24 -h urine volume of $1.5 \mathrm{~L} /$ day in adults. ${ }^{37}$ For example, using this equation, the estimated dietary intake for a hypothetical population of women with a mean UIC of $120 \mu \mathrm{g} / \mathrm{L}$ and an average body weight of $64 \mathrm{~kg}^{110}$ is $180 \mu \mathrm{g} /$ day.

\section{Estimation of iodine intake in populations using the estimated average requirement cut-point method}

Nutrient inadequacy of habitual dietary intakes, defined as the long-term average daily nutrient intakes of populations, is conventionally assessed using the EAR cutpoint method. ${ }^{107,108,111}$ This method uses the population distribution of nutrient intakes, rather than a single mean or median intake value. The percentage of individuals in a group with usual intakes below the EAR are at risk of nutrient inadequacy. ${ }^{11,112}$ The nutrient intake is satisfactory when most (97-98\%) individuals within the population meet the EAR, i.e., the acceptable prevalence of inadequate intakes is $2-3 \%$. The method assumes that the nutrient requirements in the population are normally distributed, but it does not necessarily require the nutrient intakes to follow a normal distribution, as described below. ${ }^{107}$ The underlying assumption is that the interindividual variation in requirements is lower than the inter-individual variation in intakes. ${ }^{109}$ The EAR cutpoint method has been widely applied as an evaluation tool for nutrient intakes of groups $s^{55,113,114}$ and to define the optimal fortification level of nutrients in foods. ${ }^{115}$

\section{Estimation of the prevalence of inadequate iodine intake}

The EAR cut-point method can be used to estimate the prevalence of ID based on UIC distributions, because UIC is a reliable biomarker of recent iodine intake. The population distribution of UICs is typically skewed towards lower intakes with a scattered tail of high intakes. This pattern is not only due to variations in iodine intake between individuals, but also to high day-to-day variability of the iodine intakes for each person in the studied population. The sample size of the group takes interindividual variation into account (when properly powered), but does not account for individual day-to-day variations. ${ }^{31,42}$ Therefore, before UIC data from a group can be used for the EAR cut-point method, the UIC distribution in populations with large variations in iodine intakes must be adjusted for intra-individual variation. ${ }^{55,112}$ This can be done by collecting two or more repeated samples from the same individual in a subset of the study population. The information on variability obtained can then be used to correct for within-person variation in the group. ${ }^{116}$ This approach adjusts the intake distribution closer to the mean, i.e., to more closely resemble a normal intake distribution of habitual intakes (Figure 6). ${ }^{109,112}$ 


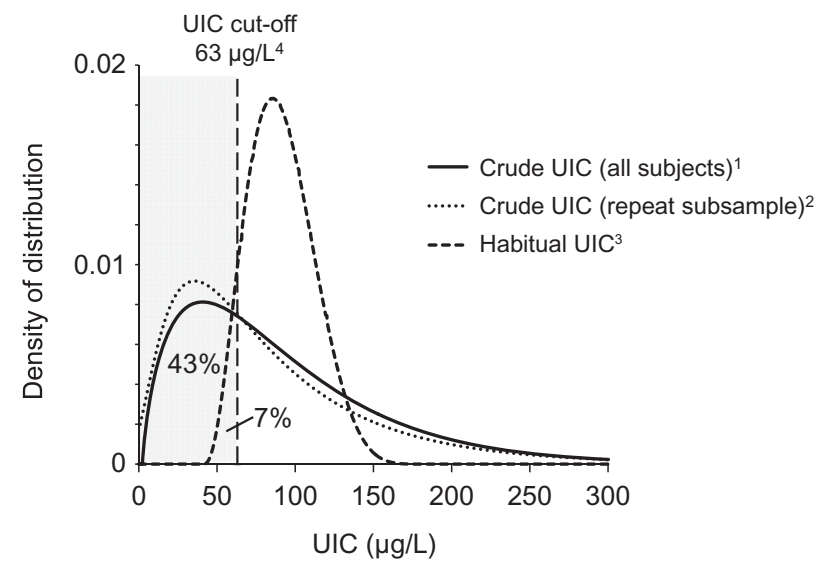

Figure 6 Population distribution of urinary iodine concentration (UIC) values in single spot urine samples ( $n=683)$, repeat single spot urine samples $(n=145)$, and after adjustment for intra- and inter-individual variation in a cross-sectional study of young Swiss women.

'Raw data UIC distribution of single individual spot urine samples $(n=683)$.

${ }^{2}$ Raw data UIC distribution of repeat single spot urine samples in a subsample $(n=145)$.

${ }^{3}$ Estimated habitual UIC distribution for the same group (adjusted by the National Cancer Institute method, using one repeat single spot sample in a subsample).

${ }^{4}$ Estimated UIC cutoff corresponding to the estimated average requirement.

The prevalence of ID can then be defined as the proportion of the population below the EAR, from the adjusted distribution (Figure 6). Normalization of the distribution generates a prevalence estimate that is closer to the true prevalence. Adjustment will generally reduce the prevalence compared to non-corrected distributions, except in populations with low or homogeneous iodine intakes. ${ }^{107}$ In populations with low iodine intake (i.e., mean intakes below the EAR), the distribution is typically skewed to lower intakes and adjustment may underestimate the prevalence. In countries with a well-functioning salt iodization program, the iodine intake is less variable and the population distribution is close to normal without correction, as observed, for example, in Swiss school children. ${ }^{44} \mathrm{~A}$ further advantage of collecting a repeat urine sample and accounting for intra-individual variation is that the required sample size can likely be smaller than the 500 samples now recommended for population assessment. ${ }^{31,42}$

Several different statistical methods to adjust the population distribution of nutrient intake data have been proposed by Iowa State University (ISU), ${ }^{117-122}$ the IOM ${ }^{108}$ and the National Cancer Institute (NCI). ${ }^{123-125}$ The strengths and limitations of the different method are outlined in earlier reviews. ${ }^{126,127}$ Tutorials to obtain estimates of usual intakes are available online from ISU, ${ }^{128}$ the Centers for Disease Control and Prevention, ${ }^{129}$ and the NCI. ${ }^{130}$ The NCI approach is currently used in the ongoing NHANES study. ${ }^{129}$ To our knowledge, only one study has used an adjustment approach to quantify variability for UIC data. ${ }^{131}$ The EAR has been used to estimate the prevalence of inadequate iodine intakes from 24-h urine collections, ${ }^{64}$ but the EAR cut-point method has not yet been evaluated for spot UIC collections.

\section{Urinary iodine concentration thresholds for the estimated average requirement cut-point method}

The UIC of each individual can be converted to daily iodine intake using the IOM formula described above and the intake distribution can be compared to the EAR. Alternatively, a UIC threshold corresponding to the EAR may be defined and used as a cut-off to estimate ID prevalence directly from the UIC population distribution. The UIC thresholds corresponding to the EAR and RDA/RNI in an average female adult population with mean weight of $64 \mathrm{~kg}^{110}$ are $63 \mu \mathrm{g} / \mathrm{L}$ and $100 \mu \mathrm{g} / \mathrm{L}$, respectively, using the simplified IOM formula (Table 3). Consequently, in a

Table 3 Recommended dietary intakes of iodine in adult women and 10-year-old girls, along with estimated corresponding urinary iodine concentration values.

\begin{tabular}{|c|c|c|c|c|}
\hline \multirow[t]{2}{*}{ Recommendation } & \multicolumn{2}{|l|}{ Adult women } & \multicolumn{2}{|l|}{ 10-year-old girls } \\
\hline & $\begin{array}{l}\text { Recommended dietary } \\
\text { intake ( } \mu \mathrm{g} / \text { day) }\end{array}$ & $\mathrm{UIC}^{\mathrm{a}}(\mu \mathrm{g} / \mathrm{L})$ & $\begin{array}{l}\text { Recommended dietary } \\
\text { intake ( } \mu \mathrm{g} / \text { day) }\end{array}$ & $\mathrm{UIC}^{\mathrm{a}}(\mu \mathrm{g} / \mathrm{L})$ \\
\hline $\mathrm{EAR}^{\mathrm{b}}$ & 95 & 63 & 73 & 94 \\
\hline $\mathrm{RDA} / \mathrm{RNI}^{\mathrm{b}, \mathrm{c}}$ & 150 & 100 & 120 & 156 \\
\hline Tolerable UL ${ }^{b}$ & 1,100 & 731 & 600 & 774 \\
\hline \multicolumn{5}{|c|}{$\begin{array}{l}{ }^{a} \text { Values calculated from dietary intake recommendations using the following equation: UIC }(\mu \mathrm{g} / \mathrm{l})=\text { iodine intake }(\mu \mathrm{g} / \mathrm{day}) /(0.0235 * \\
\text { weight }[\mathrm{kg}])^{53} \text { in a population of women with a mean weight of } 64 \mathrm{~kg}^{110} \text { or a population of } 10 \text {-year-old girls with a mean weight of } \\
33 \mathrm{~kg} .{ }^{132} \\
{ }^{\mathrm{b}} \text { Data from the Institute of Medicine. }{ }^{53} \\
\text { ' Data from the World Health Organization. }{ }^{17} \\
\text { Abbreviations: EAR, estimated average requirement; RDA, recommended daily allowance; RNI, recommended nutrient intake; UL, upper } \\
\text { level. }\end{array}$} \\
\hline
\end{tabular}


population with $2-3 \%$ of adult women with usual UICs below the EAR-UIC threshold of $63 \mu \mathrm{g} / \mathrm{L}$, the mean/ median UIC will be around $100 \mu \mathrm{g} / \mathrm{L}$, after adjustment for day-to-day variation.

Using the same approach, the UIC thresholds corresponding to the EAR and RDA/RNI in an average population of 10-year-old girls with a mean weight of $33 \mathrm{~kg}^{132}$ are $94 \mu \mathrm{g} / \mathrm{L}$ and $155 \mu \mathrm{g} / \mathrm{L}$, respectively (Table 3 ). If the same IOM formula is applied to the male population with a mean weight of $81 \mathrm{~kg}^{110}$ the estimated EAR-UIC cutoff is $50 \mu \mathrm{g} / \mathrm{L}$. Adequate iodine intakes in a male population would then be defined as a mean/median UIC of $>80 \mu \mathrm{g} / \mathrm{L}$. However, weight is a poor indicator of urine volume and the average urine volume is $1.5 \mathrm{~L} /$ day for both men and women. ${ }^{37}$ The UIC-EAR cut off corresponding to a urine volume of $1.5 \mathrm{~L} /$ day would be $57 \mu \mathrm{g} / \mathrm{L}$ for adults. However, the larger the urine volume, the lower the cut-off.

The UIC thresholds outlined here to define the prevalence of ID in an adult population are rough estimates calculated for illustrative purposes only. The optimal threshold remains to be defined based on population studies with actual data. However, the examples illustrate that the UIC threshold of $100 \mu \mathrm{g} / \mathrm{L}$ used by WHO to define ID is likely relevant to define iodine status of the population based on the median/mean UIC, but the $100 \mu \mathrm{g} / \mathrm{L}$ cut-off does not correspond to the EAR for adults. The present WHO threshold is too high to define ID in adult populations and clearly overestimates the prevalence of ID in adults.

At present, there are no UIC thresholds defined to estimate the prevalence of individuals with excessive iodine intakes. An approach similar to the EAR cut-point method may prove useful based on extrapolations from the upper tail of the UIC distribution and the tolerable upper intake level (UL).

\section{The estimated average requirement cut-point method in practice: an example from Switzerland}

The practical application of the EAR cut-point method is illustrated by data from a cross-sectional convenience sample of 683 healthy young women in the Zurich area of Switzerland ${ }^{133}$ (Table 4). All women provided a single spot urine sample, and a subsample of $20 \%$ of the participants $(n=145)$ additionally provided a second urine sample. The median UIC was $79 \mu \mathrm{g} / \mathrm{L}(n=683)$ for the first sample and $70 \mu \mathrm{g} / \mathrm{L}(n=145)$ for the repeat sample (Figure 6). The UIC distribution of the two separate urine collections was skewed due to high day-to-day variation..$^{31}$ However, since one repeat UIC was available for a subsample of the study participants, the populationspecific intra- and inter-individual variance could be
Table 4 Urinary iodine concentration values in a population of young Swiss women.

\begin{tabular}{lc}
\hline Characteristics & $\begin{array}{l}\text { Value } \\
(n=683)\end{array}$ \\
\hline Age (years) & $25.4 \pm 5.5^{\mathrm{a}}$ \\
Weight $(\mathrm{kg})$ & $61.0 \pm 8.6^{\mathrm{a}}$ \\
Height $(\mathrm{m})$ & $167.2 \pm 6.3^{\mathrm{a}}$ \\
Body mass index $\left(\mathrm{kg} / \mathrm{m}^{2}\right)$ & $21.8 \pm 2.8^{\mathrm{a}}$ \\
Crude UIC, from raw data $(\mu \mathrm{g} / \mathrm{L})$ & \\
$\quad$ Median & $79(3-621)^{\mathrm{b}}$ \\
$\quad$ Percent $<100 \mu \mathrm{g} / \mathrm{L}$ & 61 \\
$\quad$ Percent $<63 \mu \mathrm{g} / \mathrm{L}$ & 41 \\
Adjusted UIC $(\mu \mathrm{g} / \mathrm{L})$ & $90(28-244)^{\mathrm{b}}$ \\
$\quad$ Median & 67 \\
$\quad$ Percent $<100 \mu \mathrm{g} / \mathrm{L}$ & 7 \\
$\quad$ Percent $<63 \mu \mathrm{g} / \mathrm{L}$ & \\
\hline${ }^{\mathrm{a}}$ Mean \pm SD. & \\
${ }^{\mathrm{b}}$ Median (range). & \\
Values represent unpublished UIC data collected in the study \\
by Andersson et al. ${ }^{133}$
\end{tabular}

obtained and used to adjust the UIC distribution to reflect the habitual iodine intake.

We estimated the usual UIC in the study population using the NCI SAS method (SAS Institute, Inc., Cary, NC). ${ }^{123,130,134}$ The NCI method involves two steps. The first step is a model for repeated measures (Mixtran macro) obtaining variance estimates and with the possibility to include covariates. The second step (Distrib macro) estimates the distribution of usual UIC using the variance from the first step and the prevalence below given thresholds. The NCI method (using the Indivit macro) can also be used to calculate the individual's estimated usual UIC using parameters from the first step. ${ }^{135}$

The obtained UIC distribution resembled a normal distribution with an adjusted median/mean UIC of $90 \mu \mathrm{g} / \mathrm{L}$ (Figure 6). The proportion of women with a UIC $<63 \mu \mathrm{g} / \mathrm{L}$ was $41 \%$ in the raw data, but reduced to $7 \%$ using the adjusted distribution. This means that $7 \%$ of the women have low iodine intakes and are iodine deficient. The proportion of individuals with a UIC $<100 \mu \mathrm{g} / \mathrm{L}$ was $61 \%$ in the unadjusted and $67 \%$ in the adjusted distribution, i.e., the WHO UIC cut-off overestimates the "true" prevalence of ID tenfold for both distributions. The iodine intake estimated from the median UIC of the usual UIC distribution was $135 \mu \mathrm{g} /$ day, using the IOM formula. To achieve a population distribution with $2-3 \%$ below the EAR, the women would need to increase their iodine intake by $10 \mu \mathrm{g} /$ day, on average, to $145 \mu \mathrm{g} /$ day (Figure 7). This amount corresponds to the iodine content in one glass of milk. ${ }^{78}$ The resulting median UIC with extra $10 \mu \mathrm{g}$ dietary iodine per day is $97 \mu \mathrm{g} / \mathrm{L}$ and agrees well with the WHO cut-off of $100 \mu \mathrm{g} / \mathrm{L}$. But, as stressed above, the UIC depends on the urine volume and, in adults, the optimal median UIC corresponding to an adequate 


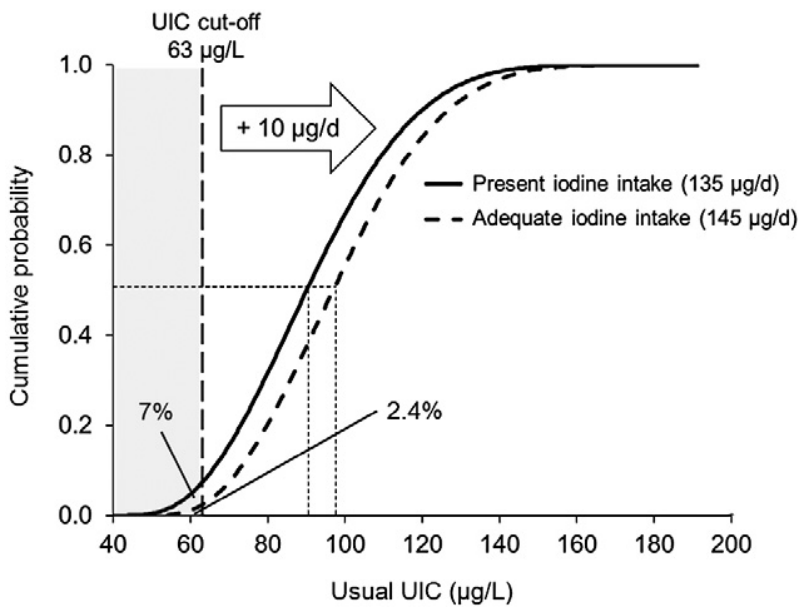

Figure 7 Cumulative probability of iodine deficiency in young Swiss women at present borderline low iodine intakes and after a theoretical increase of $10 \mu \mathrm{g} /$ day to an overall adequate iodine intake. UIC curves represent measured and adjusted usual UIC $(n=683)$. The estimated UIC cutoff corresponds to the estimated average requirement.

iodine intake has to be revisited. None of the women had usual intakes above the UL, and the data illustrate that a well-functioning salt iodization program like the one in Switzerland can meet the iodine requirements and pose no risk for excessive iodine intakes.

\section{Outlook for application of the EAR cut-point method}

Applying the EAR cut-point method to UIC distributions may be a promising approach to improving iodine monitoring in populations, but it needs to be validated, and studies to do this are underway. Testing of the different methods to adjust UIC distributions and evaluate the sample size and the number of repeated samples needed for adjustment will be conducted. Plans are also in place to validate the UIC distribution against 24 -h urine collections, UIE, urine volume, body weight, and dietary intake data in populations with different iodine status and to define the UIC cut-off corresponding to the EAR for different age- and population groups. The threshold to define ID will additionally be validated against thyroid function.

\section{Dried blood spot thyroglobulin}

The ultimate goal of an iodized salt program is to correct thyroid dysfunction caused by ID in populations, and to ensure adequate thyroid hormone for optimal growth, development, and health. Although a low median UI and/or poor household coverage with iodized salt suggest a population is at higher risk of developing thyroid dis- orders due to ID, these exposure markers do not provide direct information on thyroid function. A functional biomarker of thyroid status would complement the exposure biomarkers and would improve monitoring of ID.

Ideally, a functional biomarker of iodine status should be "field-friendly." Most thyroid function tests can be measured in just a few drops of blood from a finger or heel stick. Dried blood spots (DBS) on filter paper are increasingly used in health surveys. This collection method eliminates the need for venipuncture and cold chain/refrigeration of specimens; it also simplifies field collection, storage and transport to the laboratory, and usually reduces costs.

Thyroglobulin ( $\mathrm{Tg}$ ) is synthesized only in the thyroid, and is the most abundant intrathyroidal protein. In iodine sufficiency, small amounts of Tg are secreted into the circulation, and serum $\mathrm{Tg}$ is normally $<10 \mu \mathrm{g} /$ $\mathrm{L} .{ }^{136} \mathrm{In}$ areas of endemic goiter, serum $\mathrm{Tg}$ increases due to greater thyroid cell mass and TSH stimulation (Figure 5). Serum Tg is well correlated with the severity of ID, as measured by UI. ${ }^{137}$ Intervention studies examining the potential of $\mathrm{Tg}$ as an indicator of response to iodized oil or iodized salt have shown that $\mathrm{Tg}$ falls rapidly with iodine repletion ${ }^{138,139}$ and that $\mathrm{Tg}$ is a more sensitive indicator of iodine repletion than TSH or T4. However, commercially available assays measure serum $\mathrm{Tg}$, which requires venipuncture, centrifugation, and frozen sample transport, which may be difficult in remote areas.

A new assay for Tg has been developed for DBS, thereby simplifying collection and transport. ${ }^{139}$ In prospective studies, DBS Tg has been shown to be a sensitive measure of iodine status and reflects improved thyroid function within several months after iodine repletion. ${ }^{139,140}$ The method is simple and robust. A drop of blood from a finger stick (or a venipuncture sample) is spotted onto filter paper and the spots are allowed to dry at room temperature before being stored in sealed lowdensity polyethylene bags; the bags are preferably refrigerated at $4^{\circ} \mathrm{C}$, but they can also be stored for several weeks at cool, dry room temperatures before analysis.

Standard reference material for the DBS-Tg assay is now available and DBS-Tg is stable when stored for up to 1 year at temperatures $\leq-20^{\circ} \mathrm{C} \cdot{ }^{140}$ An international reference range has been established in iodine-sufficient 5-14-year-old children that can be used for monitoring iodine nutrition. ${ }^{140}$ The DBS-Tg reference interval for iodine-sufficient school-age children is $4-40 \mu \mathrm{g} / \mathrm{L} .{ }^{17}$ WHO now recommends DBS Tg for the monitoring of iodine status in SAC. ${ }^{17}$ However, several questions need to be resolved before $\mathrm{Tg}$ can be widely adopted as an indicator of iodine status. First, it is unclear how the WHO reference range should be applied in the context of population iodine monitoring, and how varying severity of ID in populations affects the distribution of DBS Tg 
and the percentage of children with DBS Tg values above the reference range. Another question is the need for concurrent measurement of anti-Tg antibodies to avoid potential underestimation of Tg; it is unclear how prevalent anti-Tg antibodies are in ID, or whether they are precipitated by iodine prophylaxis. Another limitation is large interassay variability, even with the use of standardization. If future research can clarify these issues, the DBS-Tg assay may prove a useful complement to the use of UIC/EAR distributions and GR for iodine monitoring, in that UIC is a sensitive indicator of recent iodine intake (days) and $\mathrm{Tg}$ shows an intermediate response (weeks to months), whereas changes in the GR reflect long-term iodine nutrition (months to years).

\section{CONCLUSION}

The global efforts to control ID have been remarkably successful. Although severe endemic goiter has largely disappeared in most parts of the world, mild-tomoderate ID continues to affect 32 countries, more than half of which are in the industrialized world. Iodine intakes in the United States, the United Kingdom, Australia, and New Zealand have fallen in recent years, mainly due to reluctance of the food industry to use iodized salt. Ensuring sustainability in countries with successful programs requires regular surveillance and occasional adjustments to the iodine content in salt. On the other hand, as salt iodization spreads across the globe, over-iodized salt has contributed to excess iodine intakes in a number of countries and regions, and both iodine deficiency and excess can damage health. Now more than ever, accurate and reliable methods to monitor iodine status are needed.

Yet current assessment methods have clear limitations, as discussed in this review. What is needed at the population level is an accurate biomarker of exposure, to define iodine intake distributions, along with a functional biomarker of thyroid status that responds to varying levels of exposure. Both biomarkers need to be robust, inexpensive, and field friendly. The exposure biomarker (UICs in spot samples from the target population) is already well established and widely used; however, it is suggested here that UIC survey data can be extrapolated to iodine intakes and then interpreted using the EAR cut-point model. This would allow national programs to derive accurate information on the prevalence of ID in the population and to quantify the necessary increase in iodine intakes to ensure sufficiency in the population. If program resources are available, the DBS-Tg assay provides a functional biomarker that can be used in combination with UIC data to ensure that thyroid function has normalized in response to improvements in iodine intakes. Sensitive biomarkers remain particularly important for iodine, as efforts to reduce salt intake to lower cardiovascular disease risk are implemented and iodized salt interventions may need to be adjusted accordingly. The median UIC in SAC is not a reasonable proxy for iodine status in the general population, and a future challenge in the field will be to expand the use of new biomarkers to pregnant women and infants.

\section{Acknowledgments}

The authors thank Max Haldimann, Isabelle Aeberli, and the members of the Iodine Task Force for advice during the preparation of this manuscript.

Funding. This research was primarily funded by the ETH Zurich, Switzerland. Additional support came from the International Council for the Control of Iodine Deficiency Disorders (ICCIDD), Zurich, Switzerland.

Declaration of interest. The authors have no relevant interest to declare.

\section{REFERENCES}

1. Caulfield LE, Richard SA, Rivera JA, et al. Stunting, wasting, and micronutrient deficiency disorders. In: Dean T, Jamison DT, Breman JG, et al., eds. Disease Control Priorities in Developing Countries. 2nd ed. New York: Oxford University Press; 2006:551-568.

2. World Health Organization. Study-group on endemic goitre; final report. Bull World Health Organ. 1953;9:293-301.

3. United Nations Children's Fund. World Declaration on the Survival, Protection and Development of Children: The World Summit for Children, New York, 30 September 1990. New York: United Nations Children's Fund (UNICEF); 1990.

4. World Health Organization. Overcoming iodine deficiency disorders. Resolution WHA39.31. In: Proceedings of the Forty-third World Health Assembly, Geneva, 7-17 May 1990. Geneva: World Health Organization; 1990.

5. United Nations Children's Fund. Proceedings of Ending Hidden Hunger: A Policy Conference on Micronutrient Malnutrition, Montreal, 10-12 October 1991. Atlanta, GA: The Task Force for Child Survival and Development; 1991.

6. World Health Organization, United Nations Children's Fund, and the International Council for the Control of lodine Deficiency Disorders. Indicators for Assessment of lodine Deficiency Disorders and Their Control Programmes: Report of a Joint WHO/UNICEF/ICCIDD Consultation, 3-5 November 1992. Geneva: World Health Organization; 1993. Document WHO/NUT/93.1.

7. Walker SP, Wachs TD, Gardner JM, et al. Child development: risk factors for adverse outcomes in developing countries. Lancet. 2007;369:145-157.

8. World Health Organization, United Nations Children's Fund, and the International Council for the Control of lodine Deficiency Disorders. Global Prevalence of lodine Deficiency Disorders. Micronutrient Deficiency Information SystemWorking Paper 1. Geneva, Switzerland: World Health Organization; 1993. Publication no. WHO/NUT/95.3.

9. Andersson $\mathrm{M}$, Karumbunathan V, Zimmermann MB. Global iodine status in 2011 and trends over the past decade. J Nutr. 2012;142:744-750.

10. United Nations Children's Fund. The State of the World's Children 2012: Children in an Urban World. New York: United Nations Children's Fund (UNICEF); 2012.

11. United Nations Children's Fund. Universal Salt lodization in Central and Eastern Europe and the Commonwealth of Independent States. Experiences, Achievements, and Lessons Learned During the Decade 2000-2009. Geneva: UNICEF Regional Office for Central and Eastern Europe and the Commonwealth of Independent States; 2011.

12. Zimmermann MB, Wegmuller R, Zeder C, et al. Rapid relapse of thyroid dysfunction and goiter in school-age children after discontinuation of salt iodization. Am J Clin Nutr. 2004;79:642-645.

13. World Health Organization. Sustaining the elimination of iodine deficiency disorders. Resolution WHA58.24. In: Fifty-eighth World Health Assembly, Geneva, 25 
May 2005. Geneva: World Health Organization; 2005:100-101. Publication no. WHA58/2005/REC/1.

14. Food and Agriculture Organization. Report of the Third Conference on Nutrition Problems in Latin America, Caracas, Venezuela, 19-28 October 1953. Issue 8 of FAO Nutrition Meetings Report Series: Issue 8. Rome: Food and Agriculture Organization of the United Nations; 1954

15. Perez C, Scrimshaw NS, Muñoz JA. Technique of endemic goiter surveys. In: Clements FW, De Moerloose J, De Smet MP, et al., eds. Endemic Goiter. Geneva: World Health Organization; 1960:369-384.

16. Delange $F$, Bastani $S$, Benmiloud $M$, et al. Definitions of endemic goitre and cretinism, classification of goitre size and severity of endemias, and survey techniques. In: Dunn JT, Pretell E, Daza CH, et al., eds. Towards the Eradication of Endemic Goiter, Cretinism, and lodine Deficiency. Proceedings of the Fifth Meeting of the Pan American Health Organization (PAHO)/World Health Organization (WHO) Technical Group on Endemic Goiter, Cretinism, and lodine Deficiency, Lima, Peru, November 1983. Washington, DC: Pan American Health Organization; 1986: 373-376. Scientific publication no. 502.

17. World Health Organization, United Nations Children's Fund, and the International Council for the Control of lodine Deficiency Disorders. Assessment of lodine Deficiency Disorders and Monitoring their Elimination: A Guide for Programme Managers. 3rd ed. Geneva: World Health Organization; 2007. ISBN: 9789241595827

18. Zimmermann M, Saad A, Hess S, et al. Thyroid ultrasound compared with World Health Organization 1960 and 1994 palpation criteria for determination of goiter prevalence in regions of mild and severe iodine deficiency. Eur J Endocrinol. 2000;143:727-731.

19. Zimmermann MB, Hess SY, Molinari $L$, et al. New reference values for thyroid volume by ultrasound in iodine-sufficient schoolchildren: a World Health Organization/Nutrition for Health and Development lodine Deficiency Study Group Report. Am J Clin Nutr. 2004;79:231-237.

20. Brunn J, Block U, Ruf G, et al. Volumetrie der Schilddrüsenlappen mittels Realtime-Sonographie. Dtsch Med Wochenschr. 1981;106:1338-1340.

21. Zimmermann MB, Molinari L, Spehl M, et al. Toward a consensus on reference values for thyroid volume in iodine-replete schoolchildren: results of a workshop on inter-observer and inter-equipment variation in sonographic measurement of thyroid volume. Eur J Endocrinol. 2001;144:213-220.

22. Aghini-Lombardi F, Antonangeli L, Pinchera A, et al. Effect of iodized salt on thyroid volume of children living in an area previously characterized by moderate iodine deficiency. J Clin Endocrinol Metab. 1997;82:1136-1139.

23. Zimmermann MB, Hess SY, Adou P, et al. Thyroid size and goiter prevalence after introduction of iodized salt: a 5-y prospective study in schoolchildren in Cote d'Ivoire. Am J Clin Nutr. 2003;77:663-667.

24. Jooste PL, Weight MJ, Lombard CJ. Short-term effectiveness of mandatory iodization of table salt, at an elevated iodine concentration, on the iodine and goiter status of schoolchildren with endemic goiter. Am J Clin Nutr. 2000;71: 75-80.

25. Pan American Health Organization (PAHO)/World Health Organization (WHO) Technical Group on Endemic Goiter, Cretinism, and lodine Deficiency. In: Dunn JT, Pretell EA, Daza CH, et al., eds. Towards the Eradication of Endemic Goiter, Cretinism, and lodine Deficiency: Proceedings of the Fifth Meeting of the PAHO/WHO Technical Group on Endemic Goiter, Cretinism, and lodine Deficiency, Lima, Peru, November 1983. Washington, DC: Pan American Health Organization; 1986:419.

26. Hetzel BS. lodine deficiency disorders (IDD) and their eradication. Lancet. 1983; 2:1126-1129.

27. Nath SK, Moinier B, Thuillier F, et al. Urinary excretion of iodide and fluoride from supplemented food grade salt. Int J Vitam Nutr Res. 1992;62:66-72.

28. Jahreis G, Hausmann W, Kiessling G, et al. Bioavailability of iodine from normal diets rich in dairy products - results of balance studies in women. Exp Clin Endocrinol Diabetes. 2001;109:163-167.

29. Vejbjerg $\mathrm{P}$, Knudsen $\mathrm{N}$, Perrild $\mathrm{H}$, et al. Estimation of iodine intake from various urinary iodine measurements in population studies. Thyroid. 2009;19:12811286.

30. Bourdoux P. Evaluation of the iodine intake: problems of the iodine/ creatinine ratio - comparison with iodine excretion and daily fluctuations of iodine concentration. Exp Clin Endocrinol Diabetes. 1998;106(Suppl 3): S17-S20.

31. König F, Andersson M, Hotz K, et al. Ten repeat collections for urinary iodine from spot samples or 24-h samples are needed to reliably estimate individual iodine status in women. J Nutr. 2011;141:2049-2054.

32. Hetzel BS, Dunn JT, Stanbury JS, eds. The Prevention and Control of lodine Deficiency Disorders. Amsterdam, The Netherlands: Elsevier; 1987.

33. Prevention and control of iodine deficiency disorders. Lancet. 1986;2:433-434

34. Bourdoux P. Measurement of iodine in the assessment of iodine deficiency. IDD Newsl. 1988;4:8-12.

35. Ascoli W, Arroyave G. Epidemiologia el bocio endémico en Centro América. Relación entre prevalencia y excreción urinaria de yodo [Epidemiology of endemic goiter in Central America. Association between prevalence and urinary iodine excretion]. Arch Latinoam Nutr. 1970;20:309-320.
36. Johner SA, Shi L, Remer T. Higher urine volume results in additional renal iodine loss. Thyroid. 2010;20:1391-1397.

37. Manz F, Johner SA, Wentz $A$, et al. Water balance throughout the adult life span in a German population. Br J Nutr. 2011;107:1673-1681.

38. Langer P. Eastern and southeastern Europe. In: Stanbury JB, Hetzel BS, eds. Endemic Goiter and Endemic Cretinism. New York: John Wiley \& Sons; 1980:141153.

39. Delange F, Benker G, Caron P, et al. Thyroid volume and urinary iodine in European schoolchildren: standardization of values for assessment of iodine deficiency. Eur J Endocrinol. 1997;136:180-187.

40. World Health Organization, United Nations Children's Fund, and the International Council for the Control of lodine Deficiency Disorders. Assessment of lodine Deficiency Disorders and Monitoring Their Elimination: A Guide for Programme Managers. 2nd ed. Geneva: World Health Organization; 2001. Publication no. WHO/NHD/01.1.

41. Caldwell $\mathrm{KL}$, Makhmudov A, Jones RL, et al. EQUIP: a worldwide program to ensure the quality of urinary iodine procedures. Accred Qual Assur. 2005;10: 356-361.

42. Andersen S, Karmisholt J, Pedersen KM, et al. Reliability of studies of iodine intake and recommendations for number of samples in groups and in individuals. Br J Nutr. 2008:99:813-818.

43. Andersson M, Takkouche B, Egli I, et al. Current global iodine status and progress over the last decade towards the elimination of iodine deficiency. Bull World Health Organ. 2005;83:518-525.

44. Andersson M, Aeberli I, Wust N, et al. The Swiss iodized salt program provides adequate iodine for school children and pregnant women, but weaning infants not receiving iodine-containing complementary foods as well as their mothers are iodine deficient. J Clin Endocrinol Metab. 2010;95:5217-5224.

45. de Benoist B, McLean E, Andersson M, et al. lodine deficiency in 2007: global progress since 2003. Food Nutr Bull. 2008;29:195-202.

46. Stanbury JB, Ermans AE, Bourdoux $\mathrm{P}$, et al. lodine-induced hyperthyroidism: occurrence and epidemiology. Thyroid. 1998;8:83-100.

47. Laurberg $P$, Cerqueira $C$, Ovesen $L$, et al. lodine intake as a determinant of thyroid disorders in populations. Best Pract Res Clin Endocrinol Metab. 2010;24: $13-27$

48. Zimmermann MB. lodine deficiency. Endocr Rev. 2009;30:376-408.

49. Gowachirapant $S$, Winichagoon $P$, Wyss L, et al. Urinary iodine concentrations indicate iodine deficiency in pregnant Thai women but iodine sufficiency in their school-aged children. J Nutr. 2009;139:1169-1172.

50. Wong EM, Sullivan KM, Perrine CG, et al. Comparison of median urinary iodine concentration as an indicator of iodine status among pregnant women school-age children, and nonpregnant women. Food Nutr Bull. 2011;32:206212.

51. Caldwell KL, Makhmudov A, Ely E, et al. lodine status of the U.S. population, National Health and Nutrition Examination Survey, 2005-2006 and 2007-2008. Thyroid. 2011;21:419-427.

52. Andersson $\mathrm{M}$, de Benoist $\mathrm{B}$, et al. Prevention and control of iodine deficiency in pregnant and lactating women and in children less than 2-years-old: conclusions and recommendations of the Technical Consultation [published correction appears in Public Health Nutr. 2008;11:327]. Public Health Nutr. 2007;10: 1606-1611.

53. Institute of Medicine, Academy of Sciences, USA. Dietary Reference Intakes for Vitamin A, Vitamin K, Arsenic, Boron, Chromium, Copper, lodine, Iron, Manganese, Molybdenum, Nickel, Silicon, Vanadium and Zinc. Washington, DC: The National Academies Press; 2001.

54. Food and Nutrition Board of the Institute of Medicine of the National Academies. Dietary Reference Intakes: The Essential Guide to Nutrient Requirements. Washington, DC: The National Academies Press; 2006.

55. Murphy SP, Barr SI. Practice paper of the American Dietetic Association: using the Dietary Reference Intakes. J Am Diet Assoc. 2011;111:762-770.

56. Dworkin $\mathrm{HJ}$, Jacquez JA, Beierwaltes WH. Relationship of iodine ingestion to iodine excretion in pregnancy. J Clin Endocrinol Metab. 1966;26:13291342.

57. Harrison MT. lodine balance in man. Postgrad Med J. 1968;44:69-71.

58. Harrison MT, Harden RM, Alexander WD, et al. lodine balance studies in patients with normal and abnormal thyroid function. J Clin Endocrinol Metab. 1965;25:1077-1084.

59. Malamos B, Koutras DA, Marketos SG, et al. Endemic goiter in Greece: an iodine balance study in the field. J Clin Endocrinol Metab. 1967;27:1372-1380.

60. Vought RL, London WT. lodine intake, excretion and thyroidal accumulation in healthy subjects. J Clin Endocrinol Metab. 1967;27:913-919.

61. Fisher DA, Oddie TH. Thyroid iodine content and turnover in euthyroid subjects: validity of estimation of thyroid iodine accumulation from short-term clearance studies. J Clin Endocrinol Metab. 1969;29:721-727.

62. Fisher DA, Oddie TH. Thyroidal radioiodine clearance and thryoid iodine accumulation: contrast between random daily variation and population data. J Clin Endocrinol Metab. 1969;29:111-115.

63. Charlton K, Skeaff S. lodine fortification: why, when, what, how, and who? Curr Opin Clin Nutr Metab Care. 2011;14:618-624 
64. Johner SA, Gunther AL, Remer T. Current trends of 24-h urinary iodine excretion in German schoolchildren and the importance of iodised salt in processed foods. Br J Nutr. 2011;106:1749-1756.

65. World Health Organization, United Nations Children's Fund, and the International Council for the Control of lodine Deficiency Disorders. Recommended lodine Levels in Salt and Guidelines for Monitoring Their Adequacy and Effectiveness. Geneva:World Health Organization; 1996. Publication no. WHO/NUT/ 96.13.

66. World Health Organization. lodine Deficiency in Europe: a Continuing Public Health Problem. In: Andersson M, de Benoist B, Darnton-Hill I, et al., eds. Geneva: World Health Organization; 2007.

67. Mattes RD, Donnelly D. Relative contributions of dietary sodium sources. J Am Coll Nutr. 1991;10:383-393.

68. Brown IJ, Tzoulaki I, Candeias V, et al. Salt intakes around the world: implications for public health. Int J Epidemiol. 2009;38:791-813.

69. Institute of Medicine Committee on Strategies to Reduce Sodium Intake. Strategies to Reduce Sodium Intake in the United States. Washington, DC: The National Academies Press; 2010.

70. Thomson BM. Nutritional modelling: distributions of salt intake from processed foods in New Zealand. Br J Nutr. 2009;102:757-765.

71. Ni Mhurchu C, Capelin C, Dunford EK, et al. Sodium content of processed foods in the United Kingdom: analysis of 44,000 foods purchased by 21,000 households. Am J Clin Nutr. 2011;93:594-600.

72. Centers for Disease Control and Prevention. Vital signs: food categories contributing the most to sodium consumption - United States, 2007-2008. MMWR Morb Mortal Wkly Rep. 2012;61:92-98.

73. Rasmussen LB, Ovesen L, Christensen T, et al. lodine content in bread and salt in Denmark after iodization and the influence on iodine intake. Int J Food Sci Nutr. 2007;58:231-239.

74. Rasmussen LB, Carle A, Jorgensen T, et al. lodine intake before and after mandatory iodization in Denmark: results from the Danish Investigation of lodine Intake and Thyroid Diseases (DanThyr) study. Br J Nutr. 2008;100:166173.

75. Verkaik-Kloosterman J, van 't Veer P, Ocke MC. Simulation model accurately estimates total dietary iodine intake. J Nutr. 2009;139:1419-1425.

76. Dahl L, Opsahl JA, Meltzer HM, et al. lodine concentration in Norwegian milk and dairy products. Br J Nutr. 2003;90:679-685.

77. Pearce EN, Pino S, He X, et al. Sources of dietary iodine: bread, cows' milk, and infant formula in the Boston area. J Clin Endocrinol Metab. 2004:89:34213424 .

78. Haldimann M, Alt A, Blanc A, et al. lodine content of food groups. J Food Compos Anal. 2005;18:461-471.

79. Li M, Waite KV, Ma G, et al. Declining iodine content of milk and re-emergence of iodine deficiency in Australia. Med J Aust. 2006;184:307.

80. Schone $F$, Leiterer $M$, Lebzien $P$, et al. lodine concentration of milk in a doseresponse study with dairy cows and implications for consumer iodine intake. J Trace Elem Med Biol. 2009;23:84-92.

81. Bath SC, Button S, Rayman MP. lodine concentration of organic and conventional milk: implications for iodine intake. Br J Nutr. 2012;107:935-940.

82. Dahl L, Johansson L, Julshamn K, et al. The iodine content of Norwegian foods and diets. Public Health Nutr. 2004;7:569-576.

83. Murray CW, Egan SK, Kim H, et al. US Food and Drug Administration's Total Diet Study: dietary intake of perchlorate and iodine. J Expo Sci Environ Epidemiol. 2008;18:571-580.

84. Julshamn K, Dahl L, Eckhoff K. Determination of iodine in seafood by inductively coupled plasma/mass spectrometry. J AOAC Int. 2001;84:19761983.

85. Teas J, Pino S, Critchley A, et al. Variability of iodine content in common commercially available edible seaweeds. Thyroid. 2004;14:836-841.

86. Nagataki $\mathrm{S}$. The average of dietary iodine intake due to the ingestion of seaweeds is $1.2 \mathrm{mg} /$ day in Japan. Thyroid. 2008;18:667-668.

87. Andersen S, Guan H, Teng W, et al. Speciation of iodine in high iodine groundwater in China associated with goitre and hypothyroidism. Biol Trace Elem Res. 2009;128:95-103.

88. Henjum S, Barikmo I, Gjerlaug AK, et al. Endemic goitre and excessive iodine in urine and drinking water among Saharawi refugee children. Public Health Nutr. 2010;13:1472-1477.

89. Gowans EM, Fraser CG. Biological variation in analyte concentrations in urine of apparently healthy men and women. Clin Chem. 1987;33:847-850.

90. Ricos C, Jimenez CV, Hernandez A, et al. Biological variation in urine samples used for analyte measurements. Clin Chem. 1994;40:472-477.

91. Fordyce FM. Database of the lodine Content of Food and Diets Populated with Data from Published Literature. British Geological Survey Commissioned Report, CR/03/84N. Keyworth, Nottingham, UK: British Geological Survey; 2003.

92. Soriguer F, Gutierrez-Repiso C, Gonzalez-Romero S, et al. lodine concentration in cow's milk and its relation with urinary iodine concentrations in the population. Clin Nutr. 2011;30:44-48.

93. Gibson RS. Principles of Nutritional Assessment. New York: Oxford University Press; 2005.
94. Thompson FE, Subar AF. Dietary assessment methodology. In: Coulston AM, Boushey C, eds. Nutrition in the Prevention and Treatment of Disease, 2nd ed. London: Elsevier Academic Press; 2008:3-39.

95. Leung AM, Braverman LE, Pearce EN. A dietary iodine questionnaire: correlation with urinary iodine and food diaries. Thyroid. 2007;17:755-762.

96. Brantsaeter AL, Haugen M, Julshamn K, et al. Evaluation of urinary iodine excretion as a biomarker for intake of milk and dairy products in pregnant women in the Norwegian Mother and Child Cohort Study (MoBa). Eur J Clin Nutr. 2009;63:347-354.

97. Flynn $A$, Hirvonen $T$, Mensink $G B$, et al. Intake of selected nutrients from foods, from fortification and from supplements in various European countries [published correction appears in Food Nutr Res. 2009;53(Suppl 1):doi: 10.3402/fnr.v53i0.2129]. Food Nutr Res. 2009;53(Suppl 1):doi: 10.3402/ fnr.v53i0.2038.

98. Espeland MA, Kumanyika S, Wilson AC, et al. Statistical issues in analyzing 24-h dietary recall and 24-h urine collection data for sodium and potassium intakes. Am J Epidemiol. 2001;153:996-1006.

99. Rennie KL, Coward A, Jebb SA. Estimating under-reporting of energy intake in dietary surveys using an individualised method. Br J Nutr. 2007;97:1169-1176.

100. Bentley B. A review of methods to measure dietary sodium intake. J Cardiovasc Nurs. 2006;21:63-67.

101. WHO/PAHO Regional Expert Group for Cardiovascular Disease Prevention through Population-wide Dietary Salt Reduction. A Review of Methods to Determine the Main Sources of Salt in the Diet. 2010; Available at: http://new.paho.org/ hq/index.php?option=com_content\&task=view\&id=2015\&ltemid=1757. Accessed 21 August 2012

102. Verkaik-Kloosterman J, van 't Veer P, Ocke MC. Reduction of salt: will iodine intake remain adequate in The Netherlands? Br J Nutr. 2010;104:17121718 .

103. Schiess S, Cressey PJ, Thomson BM. Predictive modelling of interventions to improve iodine intake in New Zealand. Public Health Nutr. 2012;25:1-9.

104. Anonymous. Global iodine scorecard. IDD Newsl. 2012;40:6-8.

105. Zimmermann MB, Jooste PL, Pandav CS. lodine-deficiency disorders. Lancet. 2008:372:1251-1262.

106. Andersson M, Zimmermann MB. Influence of iodine deficiency and excess on thyroid function tests. In: Brent GA, ed. Thyroid Function Test. New York: Springer; 2010:45-70.

107. Food and Nutrition Board of the Institute of Medicine of the National Academies. Dietary Reference Intakes: Applications in Dietary Assessment. Washing ton, DC: National Academies Press; 2000.

108. Food and Nutrition Board of the Institute of Medicine of the National Academies. Dietary Reference Intakes: Applications in Dietary Planning. Washington, DC: National Academies Press; 2003.

109. Murphy SP, Guenther PM, Kretsch MJ. Using the Dietary Reference Intakes to assess intakes of groups: pitfalls to avoid. J Am Diet Assoc. 2006;106:15501553.

110. Ekelund $\mathrm{U}$, Besson $\mathrm{H}$, Luan J, et al. Physical activity and gain in abdominal adiposity and body weight: prospective cohort study in 288,498 men and women. Am J Clin Nutr. 2011;93:826-835.

111. Carriquiry AL. Assessing the prevalence of nutrient inadequacy. Public Health Nutr. 1999;2:23-33.

112. Murphy SP, Barr SI, Poos MI. Using the new Dietary Reference Intakes to assess diets: a map to the maze. Nutr Rev. 2002;60:267-275

113. de Lauzon B, Volatier JL, Martin A. A Monte Carlo simulation to validate the EAR cut-point method for assessing the prevalence of nutrient inadequacy at the population level. Public Health Nutr. 2004;7:893-900.

114. Ribas-Barba L, Serra-Majem L, Roman-Vinas B, et al. Effects of dietary assessment methods on assessing risk of nutrient intake adequacy at the population level: from theory to practice. Br J Nutr. 2009;101(Suppl 2):S64-S72.

115. Allen L, de Benoist B, Dary O, et al. Guidelines on Food Fortification with Micronutrients. 2nd ed. World Health Organization and Food and Agricultural Organization of the United Nations; 2006.

116. Murphy SP. How consideration of population variance and individuality affects our understanding of nutritional requirements in human health and disease. $J$ Nutr. 2001;131:S361-S365.

117. Nusser SM, Carriquiry AL, Dodd KW, et al. A semiparametric transformation approach to estimating usual daily intake distributions. J Am Stat Assoc. 1996;91:1440-1449.

118. Guenther PM, Kott PS, Carriquiry AL. Development of an approach for estimating usual nutrient intake distributions at the population level. J Nutr. 1997;127: 1106-1112.

119. Carriquiry AL. Estimation of usual intake distributions of nutrients and foods. J Nutr. 2003;133:S601-S608.

120. Jahns L, Carriquiry A, Arab L, et al. Within- and between-person variation in nutrient intakes of Russian and U.S. children differs by sex and age. J Nutr. 2004;134:3114-3120.

121. Jahns L, Arab L, Carriquiry A, et al. The use of external within-person variance estimates to adjust nutrient intake distributions over time and across populations. Public Health Nutr. 2005;8:69-76. 
122. Joseph ML, Carriquiry A. A measurement error approach to assess the association between dietary diversity, nutrient intake, and mean probability of adequacy. J Nutr. 2010;140:2S2094-S2101.

123. Tooze JA, Midthune D, Dodd KW, et al. A new statistical method for estimating the usual intake of episodically consumed foods with application to their distribution. J Am Diet Assoc. 2006;106:1575-1587.

124. Tooze JA, Kipnis V, Buckman DW, et al. A mixed-effects model approach for estimating the distribution of usual intake of nutrients: the $\mathrm{NCl}$ method. Stat Med. 2010;29:2857-2868.

125. Zhang S, Midthune D, Guenther PM, et al. A new multivariate measurement error model with zero-inflated dietary data, and its application to dietary assessment. Ann Appl Stat. 2011;5:1456-1487.

126. Hoffmann $\mathrm{K}$, Boeing $\mathrm{H}$, Dufour $\mathrm{A}$, et al. Estimating the distribution of usual dietary intake by short-term measurements. Eur J Clin Nutr. 2002;56(Suppl 2):S53-S62.

127. Dodd KW, Guenther PM, Freedman LS, et al. Statistical methods for estimating usual intake of nutrients and foods: a review of the theory. J Am Diet Assoc. 2006;106:1640-1650.

128. Center for Survey Statistics and Methodology. Estimation of Usual Intake Distributions. Software for Intake Distribution Estimation (SIDE). 2012; Available at: http://streaming.stat.iastate.edu/cssm/index.php?option=com_content\& view $=$ article\&id=39\&ltemid=70. Accessed 6 September 2012.

129. Centers for Disease Control and Prevention. NHANES Dietary Web Tutorial. 2012 NHANES Dietary Web Tutorial. Available at: http://www.cdc.gov/nchs/tutorials/ Dietary/. Accessed 21 August 2012.

130. National Cancer Institute. Usual Dietary Intakes: SAS Macros for Analysis of a Single Dietary Component. 2012; Available at: http://riskfactor.cancer.gov/diet/ usualintakes/macros single.html. Accessed 21 August 2012.

131. Mackerras DE, Singh GR, Eastman CJ. lodine status of Aboriginal teenagers in the Darwin region before mandatory iodine fortification of bread. Med J Aust. 2011;194:126-130.
132. Ogden CL, Kuczmarski RJ, Flegal KM, et al. Centers for Disease Contro and Prevention 2000 growth charts for the United States: improvements to the 1977 National Center for Health Statistics version. Pediatrics. 2002;109:4560.

133. Andersson $M$, Theis $W$, Zimmermann $M B$, et al. Random serial sampling to evaluate efficacy of iron fortification: a randomized controlled trial of margarine fortification with ferric pyrophosphate or sodium iron edetate. Am J Clin Nutr. 2010;92:1094-1104.

134. National Cancer Institute. Usual Dietary Intakes: The NCI Method. 2012; Available at: http://riskfactor.cancer.gov/diet/usualintakes/method.html. Accessed 21 August 2012.

135. Kipnis V, Midthune D, Buckman DW, et al. Modeling data with excess zeros and measurement error: application to evaluating relationships between episodically consumed foods and health outcomes. Biometrics. 2009;65: 1003-1010.

136. Spencer CA, Wang CC. Thyroglobulin measurement. Techniques, clinical benefits, and pitfalls. Endocrinol Metab Clin North Am. 1995;24:841-863.

137. Knudsen N, Bulow I, Jorgensen $\mathrm{T}$, et al. Serum $\mathrm{Tg}-$ a sensitive marker of thyroid abnormalities and iodine deficiency in epidemiological studies. J Clin Endocrinol Metab. 2001;86:3599-3603.

138. Benmiloud M, Chaouki ML, Gutekunst R, et al. Oral iodized oil for correcting iodine deficiency: optimal dosing and outcome indicator selection. J Clin Endocrinol Metab. 1994;79:20-24.

139. Zimmermann MB, Moretti D, Chaouki N, et al. Development of a dried wholeblood spot thyroglobulin assay and its evaluation as an indicator of thyroid status in goitrous children receiving iodized salt. Am J Clin Nutr. 2003;77:14531458.

140. Zimmermann MB, de Benoist B, Corigliano S, et al. Assessment of iodine status using dried blood spot thyroglobulin: development of reference material and establishment of an international reference range in iodine-sufficient children. J Clin Endocrinol Metab. 2006;91:4881-4887. 